Article

\title{
Anticancer Diiron Vinyliminium Complexes: A Structure-Activity Relationship Study
}

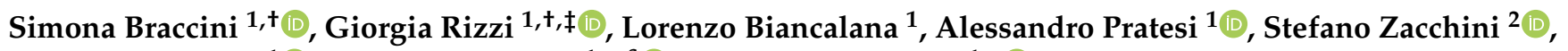

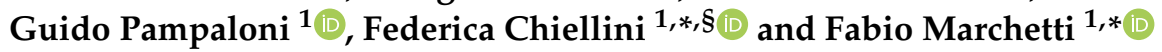

1 Department of Chemistry and Industrial Chemistry, University of Pisa, Via G. Moruzzi 13, I-56124 Pisa, Italy; simona.braccini@phd.unipi.it (S.B.); giorgia.rizzi17@gmail.com (G.R.); lorenzo.biancalana@unipi.it (L.B.); alessandro.pratesi@unipi.it (A.P.); guido.pampaloni@unipi.it (G.P.)

2 Department of Industrial Chemistry "Toso Montanari", University of Bologna, Viale Risorgimento 4, I-40136 Bologna, Italy; stefano.zacchini@unibo.it

* Correspondence: fabio.marchetti1974@unipi.it

+ These authors contribute equally to this paper.

$\ddagger$ Present address: KU Leuven-KULAK, Department of Chemistry, Molecular Imaging and Photonics, Etienne Sabbelaan 53 Box 7657, 8500 Kortrijk, Belgium.

$\S$ Deceased in March 2021.

check for

updates

Citation: Braccini, S.; Rizzi, G.;

Biancalana, L.; Pratesi, A.; Zacchini, S.;

Pampaloni, G.; Chiellini, F.; Marchetti, F.

Anticancer Diiron Vinyliminium

Complexes: A Structure-Activity Relationship Study. Pharmaceutics 2021, 13, 1158. https://doi.org/ 10.3390/pharmaceutics13081158

Academic Editor:

Vitaliy Khutoryanskiy

Received: 27 June 2021

Accepted: 23 July 2021

Published: 27 July 2021

Publisher's Note: MDPI stays neutral with regard to jurisdictional claims in published maps and institutional affiliations.

Copyright: (c) 2021 by the authors. Licensee MDPI, Basel, Switzerland. This article is an open access article distributed under the terms and conditions of the Creative Commons Attribution (CC BY) license (https:// creativecommons.org/licenses/by/ $4.0 /)$.
Abstract: A series of 16 novel diiron complexes of general formula $\left[\mathrm{Fe}_{2} \mathrm{Cp}_{2}(\mathrm{CO})(\mu-\mathrm{CO})\left\{\mu-\eta^{1}: \eta^{3}\right.\right.$ $\left.\left.\mathrm{C}\left(\mathrm{R}^{\prime}\right) \mathrm{C}\left(\mathrm{R}^{\prime \prime}\right) \mathrm{CN}(\mathrm{R})(\mathrm{Y})\right\}\right] \mathrm{CF}_{3} \mathrm{SO}_{3}(2-7)$, bearing different substituents on the bridging vinyliminium ligand, was synthesized in 69-95\% yields from the reactions of diiron $\mu$-aminocarbyne precursors with various alkynes. The products were characterized by elemental analysis, $\mathrm{IR},{ }^{1} \mathrm{H}$ and ${ }^{13} \mathrm{C}$ NMR spectroscopy; moreover the X-ray structures of $2 \mathrm{c}\left(\mathrm{R}=\mathrm{Y}=\mathrm{CH}_{2} \mathrm{Ph}, \mathrm{R}^{\prime}=\mathrm{R}^{\prime \prime}=\mathrm{Me}\right)$ and 3a $\left(\mathrm{R}=\mathrm{CH}_{2} \mathrm{CH}=\mathrm{CH}_{2}, \mathrm{Y}=\mathrm{R}^{\prime}=\mathrm{Me}, \mathrm{R}^{\prime \prime}=\mathrm{H}\right)$ were ascertained by single-crystal $\mathrm{X}$-ray diffraction studies. NMR and UV-Vis methods were used to assess the $\mathrm{D}_{2} \mathrm{O}$ solubility, the stability in aqueous solution at $37^{\circ} \mathrm{C}$ and the octanol-water partition coefficients of the complexes. A screening study evidenced a potent cytotoxicity of 2-7 against the A2780 cancer cell line, with a remarkable selectivity compared to the nontumoral Balb/3T3 cell line; complex 4c $\left(\mathrm{R}=\mathrm{Cy}, \mathrm{Y}=\mathrm{R}^{\prime}=\mathrm{R}^{\prime \prime}=\mathrm{Me}\right)$ revealed as the most performant of the series. The antiproliferative activity of a selection of complexes was also assessed on the cisplatin-resistant A2780cisR cancer cell line, and these complexes were capable of inducing a significant ROS production. Moreover, ESI-MS experiments indicated the absence of interaction of selected complexes with cytochrome $\mathrm{c}$ and the potentiality to inhibit the thioredoxin reductase enzyme $(\operatorname{Tr} x R)$.

Keywords: metal-based drugs; diiron complexes; cytotoxicity; ROS production; thioredoxin reductase inhibition

\section{Introduction}

There is an urgent demand for the development of new, effective and targeted anticancer drugs, and in this regard transition metal complexes are at the forefront of research [1-6]. Indeed, this category of compounds offers peculiar properties associated with the presence of one or more transition elements, i.e., the availability of a variety of oxidation states, coordination environments and geometries, and the possibility of replacement and/or activation of ligands under suitable conditions [7-9]. Such arsenal of tools may provide an increased added pharmaceutical value with respect to common organic molecules, and in this light few platinum complexes have been successfully employed worldwide in clinical treatments against several types of tumors, in combination with other drugs $[10,11]$. On the other hand, the toxicity of the metal center may represent a serious issue, and this is certainly the case of platinum, a "heavy metal" belonging to the $5 \mathrm{~d}$ series [12,13]. The severe side effects arising from this toxicity, along with a limited 
selectivity of action, and the tendency of the tumor cells to progressively acquire resistance to the treatment represent major inconveniences in the administration of platinum chemotherapics, besides their unquestionable efficacy [14-16]. Therefore, a huge effort has been devoted to evaluating potential drugs based on other transition metals [2]. Iron is an attractive element in this respect due to its bioavailability, which substantially limits the toxic effects of its compounds, and the feasible redox chemistry in physiological media, usually involving the $+\mathrm{II}$ and $+\mathrm{III}$ oxidation states $[17,18]$. A variety of monoiron complexes have been assessed for the anticancer potential both in vitro and in vivo [19-22]. Following the successful experience with ferroquine, a conjugate between ferrocene and the drug chloroquine, which entered phase II clinical trials as an antimalarial agent (Figure 1, structure I) $[4,23,24]$, the anticancer properties of related ferrocene derivatives have been intensively investigated (an example in Figure 1, structure II) [25-28]. This family of compounds exhibits a substantial robustness supplied by the ferrocene skeleton and exerts a cytotoxic activity essentially by unbalancing cellular redox homeostasis via iron(II) to iron(III) oxidation [25-29]. Such a mode of action strikingly differs from that of platinum compounds, which instead induce cell death through DNA binding $[10,30]$. On the wave of our longtime experience with organo-iron synthetic chemistry [31-35], in the very last years we have contributed to unveil the anticancer potential of diiron complexes, which was almost unexplored [36-40]. This is surprising, in that diiron complexes hold a major advantage, compared to related monoiron species, due to the presence of adjacent metal atoms "working in concert", thus allowing the easy construction and the stabilization of uncommon bridging ligands and the co-presence of other ligands [31,41-43]. In this context, commercial $\left[\mathrm{Fe}_{2} \mathrm{Cp}_{2}(\mathrm{CO})_{4}\right]\left(\mathrm{Cp}=\eta^{5}-\mathrm{C}_{5} \mathrm{H}_{5}\right)$ is a convenient starting material based on a $\left[\mathrm{Fe}^{+\mathrm{I}}-\mathrm{Fe}^{+\mathrm{I}}\right]$ core, with the complementary electronic properties of the $\mathrm{CO}$ and $\mathrm{Cp}$ ligands providing robustness. Cationic complexes of type III (Figure 1), containing a tightly coordinated bridging vinyliminium ligand, originate from the stepwise coupling of one isocyanide with one alkyne [44]. Complexes III are rather stable in aqueous media and display a variable cytotoxicity, ranging from the micromolar range to inactivity; they appear to exert their action following the general behavior shown by cytotoxic iron compounds, i.e., through the interference with redox processes [36-40,45]. Notwithstanding, other ways that are not accessible to ferrocene derivatives might be viable, including binding to biological targets [36-39] and the auxiliary effect of slow carbon monoxide release [37,40,45]. The structural diversity offered by the choice of the isocyanide ( $R$ substituent) and alkyne $\left(R^{\prime}, R^{\prime \prime}\right)$ reagents enables to tune important physico-chemical properties of the complexes (e.g., water solubility, amphiphilicity), correlated to their activity. A wide range of alkynes has been explored in this regard, including the incorporation of specific bioactive fragments [46], whereas the variation of the $\mathrm{R}$ group has been quite restricted (compounds with $\mathrm{R}=\mathrm{Me}$ or $\mathrm{R}=2,6-\mathrm{C}_{6} \mathrm{H}_{3} \mathrm{Me}_{2}=\mathrm{Xyl}$ have been preferentially studied). This point is not trivial, on considering that related diiron complexes with a bridging aminocarbyne (iminium) ligand (structure IV, Figure 1) possess the ability to interact with bio-substrates, which seems strongly affected by both N-substituents, $Y$ and R [37]. Herein, we report the synthesis and the full characterization of novel diiron vinyliminium complexes, containing unprecedented combinations of iminium substituents, and related studies aimed to assess the antiproliferative activity and to clarify the mechanism of action. 

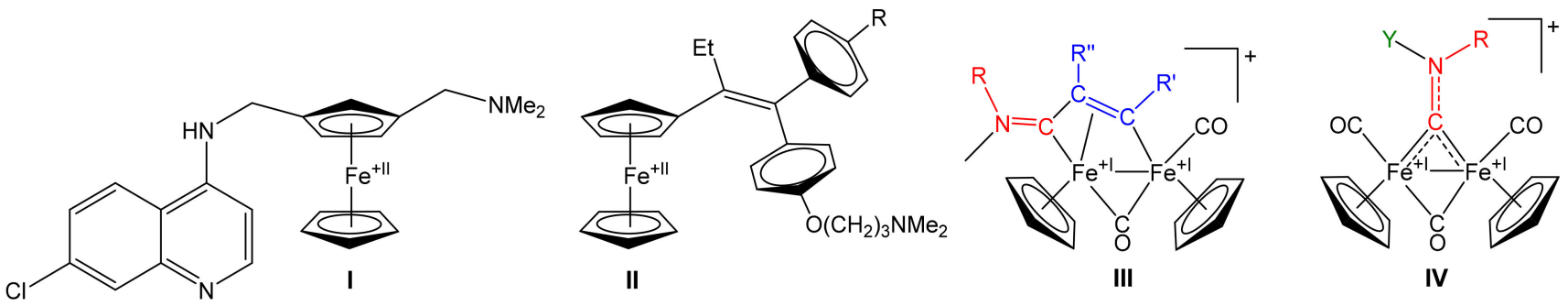

Figure 1. Structures of selected iron complexes with reported biological (anticancer) activity. a) Ferrocene derivatives: (I) ferroquine, antimalarial drug investigated in clinical trials; (II) ferrocifens $(\mathrm{R}=\mathrm{H}, \mathrm{OH})$, derived from conjugation of ferrocene with the anticancer drug tamoxifen; (III) Diiron $\mu$-vinyliminium complexes with structural variability from combination of isocyanide (CNR, red) and alkyne $\left(\mathrm{R}^{\prime} \mathrm{C} \equiv \mathrm{CR}^{\prime \prime}\right.$, blue) reagents $\left(\mathrm{R}=\mathrm{Me}, 2,6-\mathrm{C}_{6} \mathrm{H}_{3} \mathrm{Me}_{2}\right)$; (IV) Diiron $\mu$-aminocarbyne complexes able to transfer $\mathrm{Y}^{+}$(green) to bio-substrates.

\section{Experimental}

\subsection{Materials and Methods}

The preparation and purification of complexes were carried out in air, and isolated products were stored in air. Solvents and organic reactants were purchased from Merck or TCI Europe. Compounds $\mathbf{1 a}-\mathbf{c}, \mathbf{e}$ [37] and $\mathbf{1 d}, \mathbf{f}$ [47] were prepared according to the respective published procedures. Chromatography separations were carried out on columns of deactivated alumina (Merck, $4 \% w / w$ water). Infrared spectra of solutions were recorded on a Perkin Elmer Spectrum 100 FT-IR spectrometer with a $\mathrm{CaF}_{2}$ liquid transmission cell (2300-1500 $\mathrm{cm}^{-1}$ range). IR spectra were processed with Spectragryph software [48]. NMR spectra were recorded at $298 \mathrm{~K}$ on a Bruker Avance II DRX400 instrument equipped with a BBFO broadband probe. Chemical shifts (expressed in parts per million) are referenced to the residual solvent peaks $\left({ }^{1} \mathrm{H},{ }^{13} \mathrm{C}\right)[49]$ or to external standard $\left(\mathrm{H}_{3} \mathrm{PO}_{4},{ }^{31} \mathrm{P}\right) .{ }^{1} \mathrm{H}$ and ${ }^{13} \mathrm{C}$ NMR spectra were assigned with the assistance of ${ }^{1} \mathrm{H}^{-13} \mathrm{C}$ (gs-HSQC and gs-HMBC) correlation experiments [50]. NMR signals due to a second isomeric form (where it has been possible to detect them) are italicized; integration values refer to the main isomer. Schemes 1-16 show the prevalent isomeric form detected by NMR in each case. Elemental analyses were performed on a Vario MICRO cube instrument.

\subsection{Synthesis and Characterization of Diiron Complexes}

General procedure. A solution of 1a-f (ca. $0.5 \mathrm{mmol}$ ) in acetonitrile (ca. $10 \mathrm{~mL}$ ) was treated with $\mathrm{Me}_{3} \mathrm{NO}$ (1.2 eq.). The resulting mixture was stirred for $1 \mathrm{~h}$, during which time progressive color darkening was noticed. The complete conversion of the starting material into the corresponding CO/NCMe substitution product was clearly checked by IR spectroscopy [51-53]. The volatiles were removed under vacuum to afford a dark-brown residue, which was dissolved into dichloromethane (ca. $20 \mathrm{~mL}$ ) and treated with the appropriate alkyne (1.5-2.0 eq.). The mixture was stirred at room temperature for $48 \mathrm{~h}$, then it was charged on an alumina column. Elution with $\mathrm{CH}_{2} \mathrm{Cl}_{2}$ and then $\mathrm{CH}_{2} \mathrm{Cl}_{2} / \mathrm{THF}$ $(1: 1 v / v)$ allowed to remove the excess of alkyne and impurities. The fraction corresponding to the product was separated using the appropriate eluent (vide infra), then the solvent was evaporated under reduced pressure. The residue was dissolved in the minimum volume of $\mathrm{CH}_{2} \mathrm{Cl}_{2}$, and subsequent addition of hexane $(20-30 \mathrm{~mL})$ gave a powder which was dried under vacuum.

$\left[\mathrm{Fe}_{2} \mathrm{Cp}_{2}(\mathrm{CO})(\mu-\mathrm{CO})\left\{\mu-\eta^{1}: \eta^{3}-\mathrm{C}^{3}(\mathrm{Me}) \mathrm{C}^{2} \mathrm{HC}^{1} \mathrm{~N}\left(\mathrm{CH}_{2} \mathrm{Ph}\right)_{2}\right\}\right] \mathrm{CF}_{3} \mathrm{SO}_{3}, 2 \mathrm{a}$ (Scheme 1) 


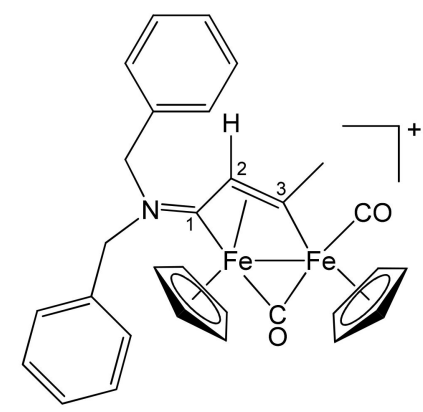

Scheme 1. Structure of the cation of $\mathbf{2 a}$.

From 1a and propyne (THF solution, ca. $1 \mathrm{~mol} / \mathrm{L}$ ). Brownish-red solid, yield $81 \%$. Eluent for chromatography: MeCN. Anal. calcd. for $\mathrm{C}_{31} \mathrm{H}_{28} \mathrm{~F}_{3} \mathrm{Fe}_{2} \mathrm{NO}_{5} \mathrm{~S}$ : C, 53.55; $\mathrm{H}, 4.06$; $\mathrm{N}, 2.01 ; \mathrm{S}, 4.61$. Found: C, 53.41; $\mathrm{H}, 4.12 ; \mathrm{N}, 1.97 ; \mathrm{S}, 4.55$. IR $\left(\mathrm{CH}_{2} \mathrm{Cl}_{2}\right): \tilde{v} / \mathrm{cm}^{-1}=1991 \mathrm{vs}$ (CO), 1808s $(\mu-\mathrm{CO}), 1644 \mathrm{~m}\left(\mathrm{C}^{1}=\mathrm{N}\right) .{ }^{1} \mathrm{H}$ NMR $\left(\right.$ acetone- $\left.\mathrm{d}_{6}\right): \delta / \mathrm{ppm}=7.44,7.21,7.10(\mathrm{~m}$, $10 \mathrm{H}, \mathrm{Ph}) ; 5.86,5.22\left(\mathrm{~d}, 2 \mathrm{H},{ }^{2} \mathrm{~J}_{\mathrm{HH}}=14.7 \mathrm{~Hz}, \mathrm{CH}_{2}\right) ; 5.66,5.32(\mathrm{~s}, 10 \mathrm{H}, \mathrm{Cp}) ; 4.90\left(\mathrm{~s}, 1 \mathrm{H}, \mathrm{C}^{2} \mathrm{H}\right)$; $4.65,4.33\left(\mathrm{~d}, 2 \mathrm{H},{ }^{2} \mathrm{~J}_{\mathrm{HH}}=14.7 \mathrm{~Hz}, \mathrm{CH}_{2}\right) ; 4.04\left(\mathrm{~s}, 3 \mathrm{H}, \mathrm{C}^{3} \mathrm{Me}\right) .{ }^{13} \mathrm{C}\left\{{ }^{1} \mathrm{H}\right\}$ NMR (acetone-d 6 ): $\delta / \mathrm{ppm}=257.1(\mu-\mathrm{CO}) ; 229.4\left(\mathrm{C}^{1}\right) ; 210.7(\mathrm{CO}) ; 210.2\left(\mathrm{C}^{3}\right) ; 132.7,132.3,129.1,129.0,128.9$, $128.8(\mathrm{Ph}) ;$ 91.2, $88.0(\mathrm{Cp}) ; 64.2,59.4\left(\mathrm{CH}_{2}\right) ; 52.9\left(\mathrm{C}^{2}\right), 41.4\left(\mathrm{C}^{3} \mathrm{Me}\right)$.

$\left[\mathrm{Fe}_{2} \mathrm{Cp}_{2}(\mathrm{CO})(\mu-\mathrm{CO})\left\{\mu-\eta^{1}: \eta^{3}-\mathrm{C}^{3}(\mathrm{Ph}) \mathrm{C}^{2} \mathrm{HC}^{1} \mathrm{~N}\left(\mathrm{CH}_{2} \mathrm{Ph}\right)_{2}\right\}\right] \mathrm{CF}_{3} \mathrm{SO}_{3}, 2 \mathrm{~b}$ (Scheme 2)

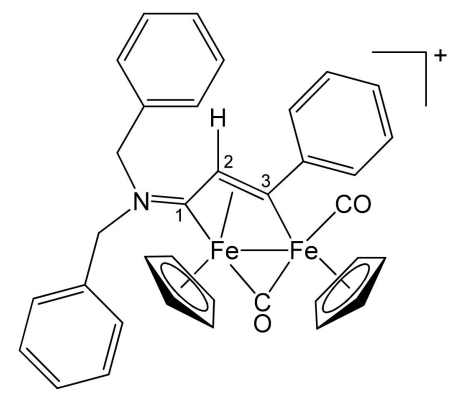

Scheme 2. Structure of the cation of $\mathbf{2 b}$.

From 1a and phenylacetylene. Brown solid, yield 81\%. Eluent for chromatography: MeCN. Anal. calcd. for $\mathrm{C}_{36} \mathrm{H}_{30} \mathrm{~F}_{3} \mathrm{Fe}_{2} \mathrm{NO}_{5} \mathrm{~S}$ : $\mathrm{C}, 57.09 ; \mathrm{H}, 3.99 ; \mathrm{N}, 1.85 ; \mathrm{S}, 4.23$. Found: $\mathrm{C}$, 56.88; H, 4.03; N, 1.88; S, 4.30. IR $\left(\mathrm{CH}_{2} \mathrm{Cl}_{2}\right): \tilde{v} / \mathrm{cm}^{-1}=1992 \mathrm{vs}(\mathrm{CO}), 1810 \mathrm{~s}(\mu-\mathrm{CO}), 1642 \mathrm{~m}\left(\mathrm{C}^{1}\right.$ $=\mathrm{N}) .{ }^{1} \mathrm{H}$ NMR $\left(\right.$ acetone- $\left.\mathrm{d}_{6}\right): \delta / \mathrm{ppm}=7.79,7.57,7.46,7.40,7.31,7.10(\mathrm{~m}, 15 \mathrm{H}, \mathrm{Ph}) ; 5.94,4.48$ $\left(\mathrm{d}, 2 \mathrm{H},{ }^{2} \mathrm{~J}_{\mathrm{HH}}=14.67 \mathrm{~Hz}, \mathrm{CH}_{2}\right) ; 5.50,5.34(\mathrm{~s}, 10 \mathrm{H}, \mathrm{Cp}) ; 5.43,4.72\left(\mathrm{~d}, 2 \mathrm{H},{ }^{2} \mathrm{~J}_{\mathrm{HH}}=13.69 \mathrm{~Hz}\right.$, $\left.\mathrm{CH}_{2}\right) ; 4.75\left(\mathrm{~s}, 1 \mathrm{H}, \mathrm{C}^{2} \mathrm{H}\right) .{ }^{13} \mathrm{C}\left\{{ }^{1} \mathrm{H}\right\} \mathrm{NMR}\left(\right.$ acetone-d $\left.\mathrm{d}_{6}\right): \delta / \mathrm{ppm}=256.6(\mu-\mathrm{CO}) ; 227.8\left(\mathrm{C}^{1}\right)$; 210.0 (CO); 156.4 (ipso-Ph); 132.8, 132.2, 129.2, 129.1, 128.4, 127.3, 127.0 (Ph); 92.2, 88.2 (Cp); $63.9,60.0\left(\mathrm{CH}_{2}\right) ; 53.5\left(\mathrm{C}^{2}\right) . \mathrm{C}^{3}$ signal overlapped with solvent.

$\left[\mathrm{Fe}_{2} \mathrm{Cp}_{2}(\mathrm{CO})(\mu-\mathrm{CO})\left\{\mu-\eta^{1}: \eta^{3}-\mathrm{C}^{3}(\mathrm{Me}) \mathrm{C}^{2}(\mathrm{Me}) \mathrm{C}^{1} \mathrm{~N}\left(\mathrm{CH}_{2} \mathrm{Ph}\right)_{2}\right\}\right] \mathrm{CF}_{3} \mathrm{SO}_{3}, 2 \mathrm{c}$ (Scheme 3)

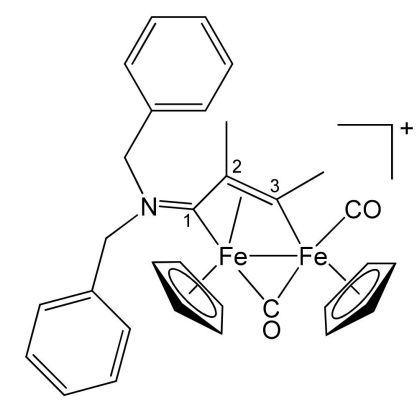

Scheme 3. Structure of the cation of $2 c$. 
From 1a and 2-butyne. Brown solid, yield 84\%. Eluent for chromatography: MeCN. Anal. calcd. for $\mathrm{C}_{32} \mathrm{H}_{30} \mathrm{~F}_{3} \mathrm{Fe}_{2} \mathrm{NO}_{5} \mathrm{~S}$ : C, 54.18; $\mathrm{H}, 4.26 ; \mathrm{N}, 1.97 ; \mathrm{S}, 4.52$. Found: $\mathrm{C}, 54.08 ; \mathrm{H}$, 4.32; $\mathrm{N}, 1.90 ; \mathrm{S}, 4.57$. IR $\left(\mathrm{CH}_{2} \mathrm{Cl}_{2}\right): \tilde{v} / \mathrm{cm}^{-1}=1987 \mathrm{vs}(\mathrm{CO}), 1805 \mathrm{~s}(\mu-\mathrm{CO}), 1628 \mathrm{~m}\left(\mathrm{C}^{1}=\mathrm{N}\right)$. ${ }^{1} \mathrm{H}$ NMR (acetone- $\left.\mathrm{d}_{6}\right): \delta / \mathrm{ppm}=7.38,7.05(\mathrm{~m}, 10 \mathrm{H}, \mathrm{Ph}) ; 5.70,5.45\left(\mathrm{~d}, 2 \mathrm{H},{ }^{2} \mathrm{~J}_{\mathrm{HH}}=14.7 \mathrm{~Hz}\right.$, $\left.\mathrm{CH}_{2}\right) ; 4.78,4.27\left(\mathrm{~d}, 2 \mathrm{H}^{2} \mathrm{~J}_{\mathrm{HH}}=15.3 \mathrm{~Hz}, \mathrm{CH}_{2}\right) ; 5.64,5.29(\mathrm{~s}, 10 \mathrm{H}, \mathrm{Cp}) ; 4.00\left(\mathrm{~s}, 3 \mathrm{H}, \mathrm{C}^{3} \mathrm{Me}\right)$; 2.19 (s, $\left.3 \mathrm{H}, \mathrm{C}^{2} \mathrm{Me}\right) .{ }^{13} \mathrm{C}\left\{{ }^{1} \mathrm{H}\right\}$ NMR (acetone-d 6$): \delta / \mathrm{ppm}=258.2(\mu-\mathrm{CO}) ; 230.4\left(\mathrm{C}^{1}\right) ; 210.9$ (CO); $203.7\left(\mathrm{C}^{3}\right) ; 132.6,131.6,128.9,128.3(\mathrm{Ph}) ; 91.6,88.6(\mathrm{Cp}) ; 65.7\left(\mathrm{C}^{2}\right)$; 63.1, $58.4\left(\mathrm{CH}_{2}\right)$; $36.8\left(\mathrm{C}^{3} \mathrm{Me}\right) ; 15.9\left(\mathrm{C}^{2} \mathrm{Me}\right)$. Crystals suitable for $\mathrm{X}$-ray analysis were obtained by slow evaporation of the solvent from an acetone solution of $\mathbf{2 c}$.

$\left[\mathrm{Fe}_{2} \mathrm{Cp}_{2}(\mathrm{CO})(\mu-\mathrm{CO})\left\{\mu-\eta^{1}: \eta^{3}-\mathrm{C}^{3}(\mathrm{Me}) \mathrm{C}^{2} \mathrm{HC}^{1} \mathrm{NMe}\left(\mathrm{CH}_{2} \mathrm{CH}=\mathrm{CH}_{2}\right)\right\}\right] \mathrm{CF}_{3} \mathrm{SO}_{3}, 3 \mathrm{a}$ (Scheme 4)

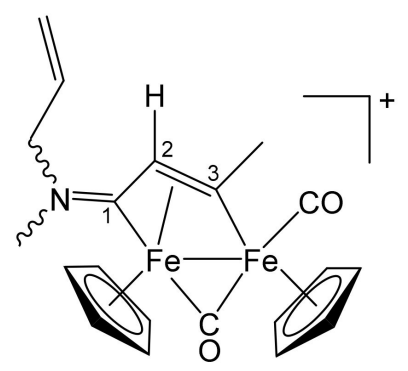

Scheme 4. Structure of the cation of $3 a$.

From $\mathbf{1 b}$ and propyne (THF solution, ca. $1 \mathrm{~mol} / \mathrm{L})$. Brown solid, yield $76 \%$. Eluent for chromatography: THF/MeCN 1:1. Anal. calcd. for $\mathrm{C}_{21} \mathrm{H}_{22} \mathrm{~F}_{3} \mathrm{Fe}_{2} \mathrm{NO}_{5} \mathrm{~S}: \mathrm{C}, 44.32 ; \mathrm{H}, 3.90 ; \mathrm{N}$, 2.46; S, 5.63. Found: $\mathrm{C}, 44.21 ; \mathrm{H}, 3.96 ; \mathrm{N}, 2.37 ; \mathrm{S}, 5.70$. IR $\left(\mathrm{CH}_{2} \mathrm{Cl}_{2}\right): \tilde{v} / \mathrm{cm}^{-1}=1990 \mathrm{vs}(\mathrm{CO})$, 1807s $(\mu-\mathrm{CO}), 1669 \mathrm{~m}\left(\mathrm{C}^{1}=\mathrm{N}\right), 1643 \mathrm{w}(\mathrm{C}=\mathrm{C}) .{ }^{1} \mathrm{H}$ NMR $\left(\right.$ acetone-d $\left.\mathrm{d}_{6}\right): \delta / \mathrm{ppm}=6.04,5.75$ $\left(\mathrm{m}, 1 \mathrm{H}, \mathrm{CH}=\mathrm{CH}_{2}\right) ; 5.61,5.51,5.49,5.39\left(\mathrm{~m}, 2 \mathrm{H}, \mathrm{CH}=\mathrm{CH}_{2}\right) ; 5.55,5.22,5.21(\mathrm{~s}, 10 \mathrm{H}, \mathrm{Cp})$; $4.98,4.90,4.17\left(\mathrm{~m},{ }^{3} \mathrm{~J}_{\mathrm{HH}}=6.4 \mathrm{~Hz}, \mathrm{NCH}_{2}\right) ; 4.70,4.67\left(\mathrm{~s}, 1 \mathrm{H}, \mathrm{C}^{2} \mathrm{H}\right) ; 3.99\left(\mathrm{~s}, 3 \mathrm{H}, \mathrm{C}^{3} \mathrm{Me}\right) ; 3.92$, $3.27(\mathrm{~s}, 3 \mathrm{H}, \mathrm{NMe})$. Isomer ratio $(\mathrm{E} / \mathrm{Z})=1.2 .{ }^{13} \mathrm{C}\left\{{ }^{1} \mathrm{H}\right\} \mathrm{NMR}\left(\right.$ acetone- $\left.\mathrm{d}_{6}\right): \delta / \mathrm{ppm}=257.3$, 256.6 ( $\mu-\mathrm{CO}) ; 227.3,226.9\left(\mathrm{C}^{1}\right) ; 210.7,208.4(\mathrm{CO}) ; 205.5\left(\mathrm{C}^{3}\right) ; 130.7,129.7\left(\mathrm{CH}=\mathrm{CH}_{2}\right) ; 121.5$, $121.3\left(\mathrm{CH}=\mathrm{CH}_{2}\right) ; 90.8,87.8$, 87.7 (Cp); 66.7, $60.4\left(\mathrm{NCH}_{2}\right) ; 52.4,52.1\left(\mathrm{C}^{2}\right)$; 47.3, $41.8(\mathrm{NMe})$; $41.2\left(\mathrm{C}^{3} \mathrm{Me}\right)$. Crystals suitable for $\mathrm{X}$-ray analysis were obtained by slow diffusion of diethyl ether into a solution of $3 \mathrm{a}$ in $\mathrm{CH}_{2} \mathrm{Cl}_{2}$, at $-30{ }^{\circ} \mathrm{C}$.

$\left[\mathrm{Fe}_{2} \mathrm{Cp}_{2}(\mathrm{CO})(\mu-\mathrm{CO})\left\{\mu-\eta^{1}: \eta^{3}-\mathrm{C}^{3}(\mathrm{Ph}) \mathrm{C}^{2} \mathrm{HC}^{1} \mathrm{NMe}\left(\mathrm{CH}_{2} \mathrm{CH}=\mathrm{CH}_{2}\right)\right\}\right] \mathrm{CF}_{3} \mathrm{SO}_{3}, 3 \mathrm{~b}$ (Scheme 5)

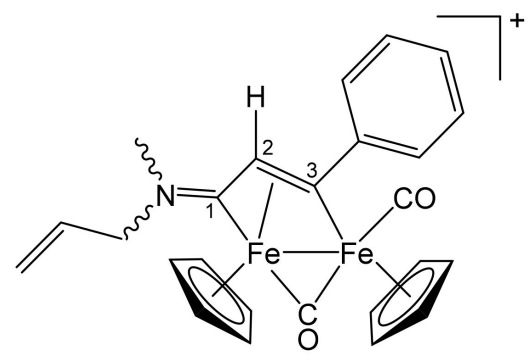

Scheme 5. Structure of the cation of $3 b$.

From $\mathbf{1 b}$ and phenylacetylene. Brown solid, yield 79\%. Eluent for chromatography: MeCN. Anal. calcd. for $\mathrm{C}_{26} \mathrm{H}_{24} \mathrm{~F}_{3} \mathrm{Fe}_{2} \mathrm{NO}_{5} \mathrm{~S}$ : C, 49.47; $\mathrm{H}, 3.83 ; \mathrm{N}, 2.22 ; \mathrm{S}, 5.08$. Found: C, 49.55; H, 3.81; N, 2.29; S, 5.13. IR $\left(\mathrm{CH}_{2} \mathrm{Cl}_{2}\right): \tilde{v} / \mathrm{cm}^{-1}=1993 \mathrm{vs}(\mathrm{CO}), 1809 \mathrm{~s}(\mu-\mathrm{CO}), 1666 \mathrm{~m}$ $\left(\mathrm{C}^{1}=\mathrm{N}\right), 1643 \mathrm{w}(\mathrm{C}=\mathrm{C}) .{ }^{1} \mathrm{H} \mathrm{NMR}\left(\mathrm{CDCl}_{3}\right): \delta / \mathrm{ppm}=7.56,7.41(\mathrm{~m}, 5 \mathrm{H}, \mathrm{Ph}) ; 5.85(\mathrm{br}, 1 \mathrm{H}$, $\left.\mathrm{CH}=\mathrm{CH}_{2}\right) ; 5.64,5.54,5.35,5.31\left(\mathrm{~m}, 2 \mathrm{H}, \mathrm{CH}=\mathrm{CH}_{2}\right) ; 5.23,5.21,4.97(\mathrm{~s}, 10 \mathrm{H}, \mathrm{Cp}) ; 4.34,4.17$ $\left(\mathrm{m}, 2 \mathrm{H}, \mathrm{NCH}_{2}\right) ; 4.76,4.69\left(\mathrm{~s}, 1 \mathrm{H}, \mathrm{C}^{2} \mathrm{H}\right) ; 3.89,3.30(\mathrm{~s}, 3 \mathrm{H}, \mathrm{NMe})$. Isomer ratio $(\mathrm{Z} / \mathrm{E})=1.4$. ${ }^{13} \mathrm{C}\left\{{ }^{1} \mathrm{H}\right\} \mathrm{NMR}\left(\right.$ acetone-d $\left.\mathrm{d}_{6}\right): \delta / \mathrm{ppm}=256.3,255.6(\mu-\mathrm{CO}) ; 226.1,225.1\left(\mathrm{C}^{1}\right) ; 210.1,210.0$ (CO); 204.4, $204.3\left(\mathrm{C}^{3}\right) ; 156.4,156.3$ (ipso-Ph); 130.7, $129.8\left(\mathrm{CH}=\mathrm{CH}_{2}\right) ; 128.4,128.3,127.4$, 127.3, 127.0, $126.9(\mathrm{Ph}) ; 121.6,121.4\left(\mathrm{CH}=\mathrm{CH}_{2}\right)$; 91.7, 87.9, $87.8(\mathrm{Cp}) ; 67.0,60.3\left(\mathrm{NCH}_{2}\right)$; 53.0, $52.8\left(\mathrm{C}^{2}\right) ; 47.7,41.8(\mathrm{NMe})$. 
$\left[\mathrm{Fe}_{2} \mathrm{Cp}_{2}(\mathrm{CO})(\mu-\mathrm{CO})\left\{\mu-\eta^{1}: \eta^{3}-\mathrm{C}^{3}(\mathrm{Me}) \mathrm{C}^{2}(\mathrm{Me}) \mathrm{C}^{1} \mathrm{NMe}\left(\mathrm{CH}_{2} \mathrm{CH}=\mathrm{CH}_{2}\right)\right\}\right] \mathrm{CF}_{3} \mathrm{SO}_{3}, 3 \mathrm{c}$ (Scheme 6)

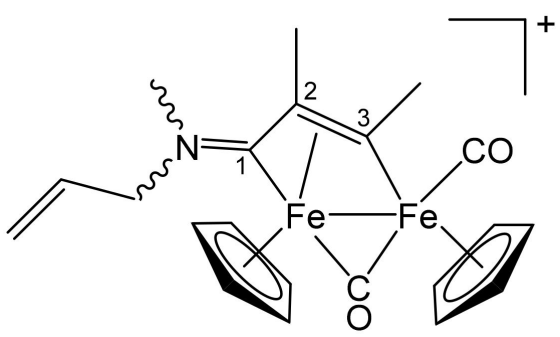

Scheme 6. Structure of the cation of 3c.

From $1 \mathrm{~b}$ and 2-butyne. Brown solid, yield 94\%. Eluent for chromatography: MeCN. Anal. calcd. for $\mathrm{C}_{22} \mathrm{H}_{24} \mathrm{~F}_{3} \mathrm{Fe}_{2} \mathrm{NO}_{5} \mathrm{~S}$ : C, 45.31; H, 4.15; N, 2.40; S, 5.50. Found: C, 45.17; H, $4.21 ; \mathrm{N}, 2.31 ; \mathrm{S}, 5.55$. IR $\left(\mathrm{CH}_{2} \mathrm{Cl}_{2}\right): \tilde{v} / \mathrm{cm}^{-1}=1986 \mathrm{vs}(\mathrm{CO}), 1805 \mathrm{~s}(\mu-\mathrm{CO}), 1656 \mathrm{~m}\left(\mathrm{C}^{1}=\mathrm{N}\right)$, $1639 \mathrm{w}(\mathrm{C}=\mathrm{C}) .{ }^{1} \mathrm{H}$ NMR $\left(\right.$ acetone- $\left.\mathrm{d}_{6}\right): \delta / \mathrm{ppm}=6.05,5.80\left(\mathrm{~m}, 1 \mathrm{H}, \mathrm{CH}=\mathrm{CH}_{2}\right) ; 5.62,5.55$, $5.41,5.38\left(\mathrm{~m}, 2 \mathrm{H}, \mathrm{CH}=\mathrm{CH}_{2}\right) ; 5.52,5.51,5.20,5.19$ (s, $\left.10 \mathrm{H}, \mathrm{Cp}\right) ; 5.05-4.87,4.20,4.03(\mathrm{~m}$, $\left.2 \mathrm{H}, \mathrm{NCH}_{2}\right) ; 3.91\left(\mathrm{~s}, 3 \mathrm{H}, \mathrm{C}^{3} \mathrm{Me}\right) ; 3.89,3.21(\mathrm{~s}, 3 \mathrm{H}, \mathrm{NMe}) ; 2.04\left(\mathrm{~s}, 3 \mathrm{H}, \mathrm{C}^{2} \mathrm{Me}\right)$. Isomer ratio $(\mathrm{Z} / \mathrm{E})=1.2 .{ }^{13} \mathrm{C}\left\{{ }^{1} \mathrm{H}\right\}$ NMR (acetone- $\left.\mathrm{d}_{6}\right): \delta / \mathrm{ppm}=258.1,257.4(\mu-\mathrm{CO}) ; 227.3,226.5\left(\mathrm{C}^{1}\right)$; 210.8, 210.6 (CO); 202.1, 201.9 (C 3$) ; 130.8,129.8\left(\mathrm{CH}=\mathrm{CH}_{2}\right) ; 121.7,121.5\left(\mathrm{CH}=\mathrm{CH}_{2}\right) ; 91.0$, 88.2, 88.1 (Cp); 65.5 ( $\left.\mathrm{C}^{2}\right)$; 65.4, 60.5 $\left(\mathrm{NCH}_{2}\right)$; 45.3, 41.3 (NMe); $36.2\left(\mathrm{C}^{3} \mathrm{Me}\right) ; 15.4,14.8\left(\mathrm{C}^{2} \mathrm{Me}\right)$.

$\left[\mathrm{Fe}_{2} \mathrm{Cp}_{2}(\mathrm{CO})(\mu-\mathrm{CO})\left\{\mu-\eta^{1}: \eta^{3}-\mathrm{C}^{3}(\mathrm{Me}) \mathrm{C}^{2} \mathrm{HC}^{1} \mathrm{NMe}(\mathrm{Cy})\right\}\right] \mathrm{CF}_{3} \mathrm{SO}_{3}$, a a (Scheme 7 )

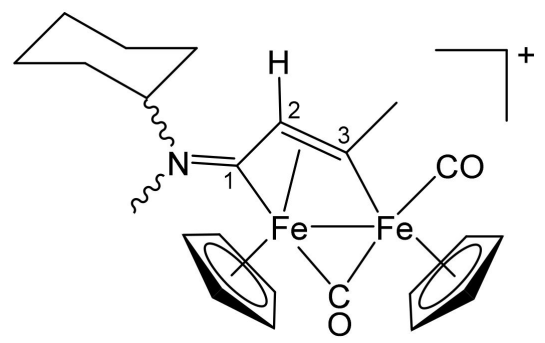

Scheme 7. Structure of the cation of $4 \mathbf{a}$.

From 1c and propyne (THF solution, ca. $1 \mathrm{~mol} / \mathrm{L}$ ). Brown solid, yield $90 \%$. Eluent for chromatography: MeCN. Anal. calcd. for $\mathrm{C}_{24} \mathrm{H}_{28} \mathrm{~F}_{3} \mathrm{Fe}_{2} \mathrm{NO}_{5} \mathrm{~S}$ : C, 47.16; $\mathrm{H}, 4.62 ; \mathrm{N}, 2.29 ; \mathrm{S}$, 5.25. Found: $\mathrm{C}, 47.02 ; \mathrm{H}, 4.70 ; \mathrm{N}, 2.23 ; \mathrm{S}, 5.31$. IR $\left(\mathrm{CH}_{2} \mathrm{Cl}_{2}\right): \tilde{v} / \mathrm{cm}^{-1}=1989 \mathrm{vs}(\mathrm{CO}), 1805 \mathrm{~s}$ $(\mu-\mathrm{CO}), 1661 \mathrm{~m}\left(\mathrm{C}^{1}=\mathrm{N}\right) .{ }^{1} \mathrm{H}$ NMR $\left(\right.$ acetone- $\left._{6}\right): \delta / \mathrm{ppm}=5.53,5.52,5.20,5.17(\mathrm{~s}, 10 \mathrm{H}, \mathrm{Cp})$; 4.81, $3.60\left(\mathrm{~m}, 1 \mathrm{H}, \mathrm{CH}^{\mathrm{Cy}}\right) ; 4.74,4.69\left(\mathrm{~s}, 1 \mathrm{H}, \mathrm{C}^{2} \mathrm{H}\right) ; 3.98$, $3.96\left(\mathrm{~s}, 3 \mathrm{H}, \mathrm{C}^{3} \mathrm{Me}\right) ; 3.90,3.20(\mathrm{~s}, 3 \mathrm{H}$, $\mathrm{NMe}) ; 2.26,2.03-1.51,1.43-1.06\left(\mathrm{~m}, 10 \mathrm{H}, \mathrm{CH}_{2}{ }^{\mathrm{Cy}}\right)$. Isomer ratio $(\mathrm{E} / \mathrm{Z})=1.2 .{ }^{13} \mathrm{C}\left\{{ }^{1} \mathrm{H}\right\} \mathrm{NMR}$ (acetone- $\left.\mathrm{d}_{6}\right): \delta / \mathrm{ppm}=257.3,256.4(\mu-\mathrm{CO}) ; 225.5,224.6\left(\mathrm{C}^{1}\right) ; 210.9,210.7(\mathrm{CO}) ; 208.2,207.9$ (CO); $204.9\left(\mathrm{C}^{3}\right)$; 90.7, 87.7, 87.5 (Cp); 75.2, $68.2\left(\mathrm{CH}^{\mathrm{Cy}}\right)$; 52.0, $51.3\left(\mathrm{C}^{2}\right)$; 42.9, 38.2 (NMe); 41.2, $41.1\left(\mathrm{C}^{3} \mathrm{Me}\right) ; 29.9,29.8,29.7,25.1,24.7,24.6,24.5\left(\mathrm{CH}_{2}{ }^{\mathrm{Cy}}\right)$.

$\left[\mathrm{Fe}_{2} \mathrm{Cp}_{2}(\mathrm{CO})(\mu-\mathrm{CO})\left\{\mu-\eta^{1}: \eta^{3}-\mathrm{C}^{3}(\mathrm{Ph}) \mathrm{C}^{2} \mathrm{HC}^{1} \mathrm{NMe}(\mathrm{Cy})\right\}\right] \mathrm{CF}_{3} \mathrm{SO}_{3}, 4 \mathrm{~b}$ (Scheme 8)

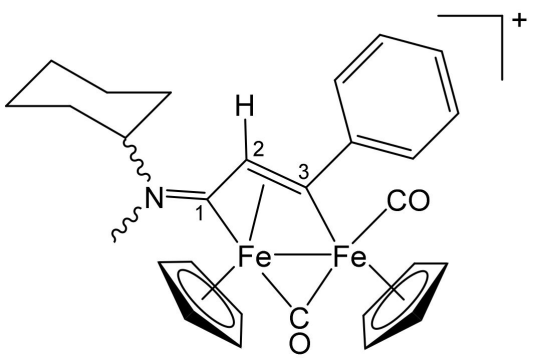

Scheme 8. Structure of the cation of $4 b$. 
From 1c and phenylacetylene. Brownish-green solid, yield 93\%. Eluent for chromatography: $\mathrm{MeCN}$. Anal. calcd. for $\mathrm{C}_{29} \mathrm{H}_{30} \mathrm{~F}_{3} \mathrm{Fe}_{2} \mathrm{NO}_{5} \mathrm{~S}: \mathrm{C}, 51.73 ; \mathrm{H}, 4.49 ; \mathrm{N}, 2.08 ; \mathrm{S}, 4.76$. Found: $\mathrm{C}, 51.68 ; \mathrm{H}, 4.53 ; \mathrm{N}, 2.12 ; \mathrm{S}, 4.69$. IR $\left(\mathrm{CH}_{2} \mathrm{Cl}_{2}\right): \tilde{v} / \mathrm{cm}^{-1}=1992 \mathrm{vs}(\mathrm{CO}), 1809 \mathrm{~s}(\mu-\mathrm{CO}), 1658 \mathrm{~m}$ $\left(\mathrm{C}^{1}=\mathrm{N}\right) .{ }^{1} \mathrm{H}$ NMR $\left(\right.$ acetone- $\left.\mathrm{d}_{6}\right): \delta / \mathrm{ppm}=7.83,7.57,7.44(\mathrm{~m}, 5 \mathrm{H}, \mathrm{Ph}) ; 5.44,5.40,5.28,5.27(\mathrm{~s}$, $10 \mathrm{H}, \mathrm{Cp}) ; 4.95,3.83\left(\mathrm{~m}, 1 \mathrm{H}, \mathrm{CH}^{\mathrm{Cy}}\right) ; 4.77,4.73\left(\mathrm{~s}, 1 \mathrm{H}, \mathrm{C}^{2} \mathrm{H}\right) ; 4.02,3.35$ (s, $\left.3 \mathrm{H}, \mathrm{NMe}\right) ; 2.3-1.1$ $\left(\mathrm{m}, 10 \mathrm{H}, \mathrm{CH}_{2}{ }^{\mathrm{Cy}}\right)$. Isomer ratio $(\mathrm{E} / \mathrm{Z})=1.2 .{ }^{13} \mathrm{C}\left\{{ }^{1} \mathrm{H}\right\} \mathrm{NMR}\left(\right.$ acetone- $\left.\mathrm{d}_{6}\right): \delta / \mathrm{ppm}=256.7$, 255.7 ( $\mu$-CO); 224.3, 223.6 (C $\mathrm{C}^{1}$ ); 210.3, 210.1 (CO); 204.5, 204.1 (C $\left.\mathrm{C}^{3}\right) ; 156.4$ (ipso-Ph); 128.3, 127.4, 127.0 (Ph); 91.7, 87.9, 87.7 (Cp); 75.5, $68.0\left(\mathrm{CH}^{\mathrm{Cy}}\right)$; 52.4, 51.8 $\left(\mathrm{C}^{2}\right)$; 43.2, 38.1 (NMe); $29.9,29.8,25.2,24.7-24.5\left(\mathrm{CH}_{2} \mathrm{Cy}\right)$.

$\left[\mathrm{Fe}_{2} \mathrm{Cp}_{2}(\mathrm{CO})(\mu-\mathrm{CO})\left\{\mu-\eta^{1}: \eta^{3}-\mathrm{C}^{3}(\mathrm{Me}) \mathrm{C}^{2}(\mathrm{Me}) \mathrm{C}^{1} \mathrm{NMe}(\mathrm{Cy})\right\}\right] \mathrm{CF}_{3} \mathrm{SO}_{3}, 4 \mathrm{c}$ (Scheme 9)

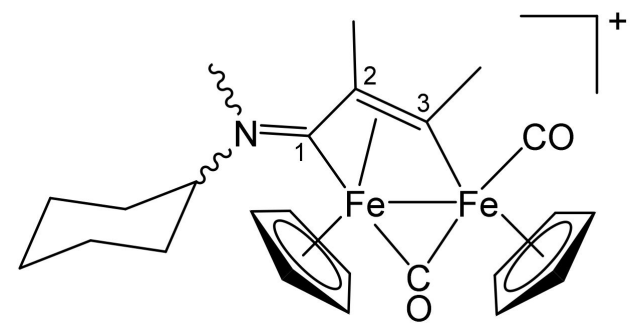

Scheme 9. Structure of the cation of $4 c$.

From 1c and 2-butyne. Brownish-green solid, yield 95\%. Eluent for chromatography: MeCN. Anal. calcd. for $\mathrm{C}_{25} \mathrm{H}_{30} \mathrm{~F}_{3} \mathrm{Fe}_{2} \mathrm{NO}_{5} \mathrm{~S}$ : $\mathrm{C}, 48.02 ; \mathrm{H}, 4.84 ; \mathrm{N}, 2.24 ; \mathrm{S}, 5.13$. Found: $\mathrm{C}$, $47.89 ; \mathrm{H}, 4.90 ; \mathrm{N}, 2.18 ; \mathrm{S}, 5.19$. IR $\left(\mathrm{CH}_{2} \mathrm{Cl}_{2}\right): \tilde{v} / \mathrm{cm}^{-1}=1986 \mathrm{vs}(\mathrm{CO}), 1805 \mathrm{~s}(\mu-\mathrm{CO}), 1646 \mathrm{~m}$ $\left(\mathrm{C}^{1}=\mathrm{N}\right) .{ }^{1} \mathrm{H}$ NMR (acetone- $\left.\mathrm{d}_{6}\right): \delta / \mathrm{ppm}=5.51,5.20,5.15(\mathrm{~s}, 10 \mathrm{H}, \mathrm{Cp}) ; 4.86,3.51(\mathrm{br}, 1 \mathrm{H}$, $\left.\mathrm{CH}^{\mathrm{Cy}}\right) ; 3.93,3.16(\mathrm{~s}, 3 \mathrm{H}, \mathrm{NMe}) ; 3.91\left(\mathrm{~s}, 3 \mathrm{H}, \mathrm{C}^{3} \mathrm{Me}\right) ; 2.2,1.9-1.1\left(\mathrm{~m}, 10 \mathrm{H}, \mathrm{CH}_{2}{ }^{\mathrm{Cy}}\right) ; 2.04,2.02$ $\left(\mathrm{s}, 3 \mathrm{H}, \mathrm{C}^{2} \mathrm{Me}\right)$. Isomer ratio $(\mathrm{Z} / \mathrm{E})=2 \cdot{ }^{13} \mathrm{C}\left\{{ }^{1} \mathrm{H}\right\} \mathrm{NMR}\left(\right.$ acetone- $\left._{6}\right): \delta / \mathrm{ppm}=258.3,257.5$ ( $\mu$-CO); 226.3, 224.4 (C $\left.\mathrm{C}^{1}\right) ;$ 211.3, 210.7 (CO); 202.2, $201.9\left(\mathrm{C}^{3}\right)$; 91.1, 88.2, 88.0 (Cp); 73.9, 68.0 $\left(\mathrm{CH}^{\mathrm{Cy}}\right) ; 64.8,64.2\left(\mathrm{C}^{2}\right) ; 40.9,36.4(\mathrm{NMe}) ; 37.3,36.2\left(\mathrm{C}^{3} \mathrm{Me}\right) ; 30.4,30.0,25.3,24.7,24.6,24.5$ $\left(\mathrm{CH}_{2}{ }^{\mathrm{Cy}}\right) ; 15.7,15.0\left(\mathrm{C}^{2} \mathrm{Me}\right)$.

$\left[\mathrm{Fe}_{2} \mathrm{Cp}_{2}(\mathrm{CO})(\mu-\mathrm{CO})\left\{\mu-\eta^{1}: \eta^{3}-\mathrm{C}^{3}(\mathrm{Me}) \mathrm{C}^{2} \mathrm{HC}^{1} \mathrm{NMe}\left(\mathrm{CH}_{2} \mathrm{Ph}\right)\right\}\right] \mathrm{CF}_{3} \mathrm{SO}_{3}, 5 \mathrm{a}$ (Scheme 10)

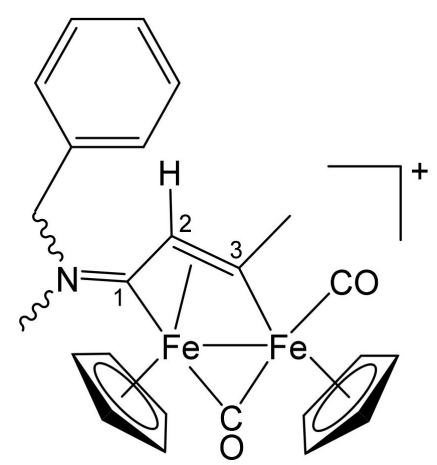

Scheme 10. Structure of the cation of $5 \mathbf{a}$.

From 1d and propyne (THF solution, ca. $1 \mathrm{~mol} / \mathrm{L}$ ). Brown solid, yield $88 \%$. Eluent for chromatography: MeCN. Anal. calcd. for $\mathrm{C}_{25} \mathrm{H}_{24} \mathrm{~F}_{3} \mathrm{Fe}_{2} \mathrm{NO}_{5} \mathrm{~S}: \mathrm{C}, 48.49 ; \mathrm{H}, 3.91 ; \mathrm{N}, 2.26 ; \mathrm{S}$, 5.18. Found: $\mathrm{C}, 48.58 ; \mathrm{H}, 3.85 ; \mathrm{N}, 2.21 ; \mathrm{S}, 5.11$. IR $\left(\mathrm{CH}_{2} \mathrm{Cl}_{2}\right): \tilde{v} / \mathrm{cm}^{-1}=1991 \mathrm{vs}(\mathrm{CO}), 1808 \mathrm{~s}$ $(\mu-\mathrm{CO}), 1664 \mathrm{~m}\left(\mathrm{C}^{1}=\mathrm{N}\right) .{ }^{1} \mathrm{H}$ NMR $\left(\right.$ acetone- $\left._{6}\right): \delta / \mathrm{ppm}=7.39-7.27,7.07(\mathrm{~m}, 5 \mathrm{H}, \mathrm{Ph}) ; 5.49$, $5.31,4.80,4.42\left(\mathrm{~d}, 2 \mathrm{H},{ }^{2} \mathrm{~J}_{\mathrm{HH}}=14.2 \mathrm{~Hz}, \mathrm{CH}_{2}\right) ; 5.25,5.01(\mathrm{~s}, 10 \mathrm{H}, \mathrm{Cp}) ; 4.74,4.65(\mathrm{~s}, 1 \mathrm{H}$, $\left.\mathrm{C}^{2} \mathrm{H}\right) ; 3.88\left(\mathrm{~s}, 3 \mathrm{H}, \mathrm{C}^{3} \mathrm{Me}\right) ; 3.62,3.00(\mathrm{~s}, 3 \mathrm{H}, \mathrm{NMe})$. Isomer ratio $(\mathrm{E} / \mathrm{Z})=1.2 .{ }^{13} \mathrm{C}\left\{{ }^{1} \mathrm{H}\right\} \mathrm{NMR}$ $\left(\right.$ acetone- $\left.\mathrm{d}_{6}\right): \delta / \mathrm{ppm}=256.8(\mu-\mathrm{CO}) ; 227.5,226.7\left(\mathrm{C}^{1}\right) ; 210.2,210.0(\mathrm{CO}) ; 209.1,208.8\left(\mathrm{C}^{3}\right)$; $132.4,131.7,129.4,129.3,129.2,129.1(\mathrm{Ph}) ; 90.5,90.4,87.9,87.8(\mathrm{Cp}) ; 68.4,61.9\left(\mathrm{CH}_{2}\right) ; 52.1$, $52.6\left(\mathrm{C}^{2}\right) ; 47.9,42.1$ (NMe); 42.4, $42.3\left(\mathrm{C}^{3} \mathrm{Me}\right)$.

$\left[\mathrm{Fe}_{2} \mathrm{Cp}_{2}(\mathrm{CO})(\mu-\mathrm{CO})\left\{\mu-\eta^{1}: \eta^{3}-\mathrm{C}^{3}(\mathrm{Me}) \mathrm{C}^{2}(\mathrm{Me}) \mathrm{C}^{1} \mathrm{NMe}\left(\mathrm{CH}_{2} \mathrm{Ph}\right)\right\}\right] \mathrm{CF}_{3} \mathrm{SO}_{3}, 5 \mathrm{~b}$ (Scheme 11) 


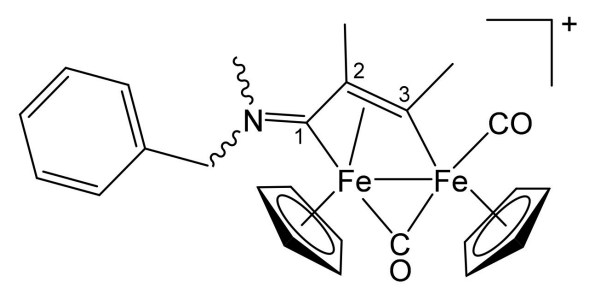

Scheme 11. Structure of the cation of $5 b$.

From 1d and 2-butyne. Brown solid, yield 70\%. Eluent for chromatography: MeCN. Anal. calcd. for $\mathrm{C}_{26} \mathrm{H}_{26} \mathrm{~F}_{3} \mathrm{Fe}_{2} \mathrm{NO}_{5} \mathrm{~S}$ : $\mathrm{C}, 49.31 ; \mathrm{H}, 4.14 ; \mathrm{N}, 2.21 ; \mathrm{S}, 5.06$. Found: $\mathrm{C}, 49.20 ; \mathrm{H}$, $4.19 ; \mathrm{N}, 2.16 ; \mathrm{S}, 5.09$. IR $\left(\mathrm{CH}_{2} \mathrm{Cl}_{2}\right): \tilde{v} / \mathrm{cm}^{-1}=1986 \mathrm{vs}(\mathrm{CO}), 1805 \mathrm{~s}(\mu-\mathrm{CO}), 1650 \mathrm{~m}\left(\mathrm{C}^{1}=\mathrm{N}\right)$. ${ }^{1} \mathrm{H}$ NMR (acetone- $\left.\mathrm{d}_{6}\right): \delta / \mathrm{ppm}=7.49-7.44,7.32(\mathrm{~m}, 5 \mathrm{H}, \mathrm{Ph}) ; 5.57,5.55,5.25,5.23(\mathrm{~s}, 10 \mathrm{H}$, $\mathrm{Cp}) ; 4.87,4.57\left(\mathrm{~d},{ }^{2} \mathrm{~J}_{\mathrm{HH}}=14.7 \mathrm{~Hz}, 2 \mathrm{H}, \mathrm{CH}_{2}\right) ; 3.95\left(\mathrm{~s}, 3 \mathrm{H}, \mathrm{C}^{3} \mathrm{Me}\right) ; 3.81,3.06$ (s, $\left.3 \mathrm{H}, \mathrm{NMe}\right)$; $2.14\left(\mathrm{~s}, 3 \mathrm{H}, \mathrm{C}^{2} \mathrm{Me}\right)$. Isomer ratio $(\mathrm{Z} / \mathrm{E})=1.5 .{ }^{13} \mathrm{C}\left\{{ }^{1} \mathrm{H}\right\} \mathrm{NMR}\left(\right.$ acetone- $\left.\mathrm{d}_{6}\right): \delta / \mathrm{ppm}=258.3$ ( $\mu$-CO); 228.5, $226.9\left(\mathrm{C}^{1}\right) ;$ 211.0, 210.7 (CO); 202.6, $202.2\left(\mathrm{C}^{3}\right)$; 133.4, 132.4 (ipso-Ph); 129.2, 129.1, 129.0, 128.9, 128.8, $128.7(\mathrm{Ph}) ; 91.2,88.3,88.2(\mathrm{Cp}) ; 65.9,61.3\left(\mathrm{C}^{2}\right) ; 65.6,65.5\left(\mathrm{CH}_{2}\right)$; 45.4, 41.6 (NMe); 36.4, 36.3 ( $\left.\mathrm{C}^{3} \mathrm{Me}\right) ; 15.5,15.0\left(\mathrm{C}^{2} \mathrm{Me}\right)$.

$\left[\mathrm{Fe}_{2} \mathrm{Cp}_{2}(\mathrm{CO})(\mu-\mathrm{CO})\left\{\mu-\eta^{1}: \eta^{3}-\mathrm{C}^{3}(\mathrm{Et}) \mathrm{C}^{2}(\mathrm{Et}) \mathrm{C}^{1} \mathrm{NMe}\left(\mathrm{CH}_{2} \mathrm{Ph}\right)\right\}\right] \mathrm{CF}_{3} \mathrm{SO}_{3}, 5 \mathrm{c}$ (Scheme 12)

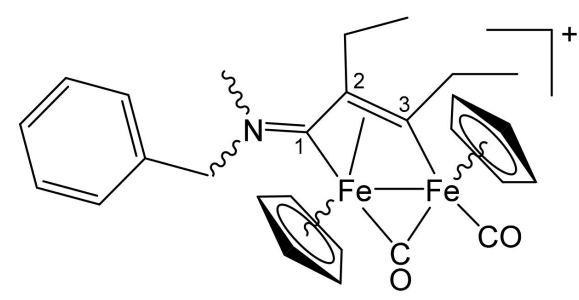

Scheme 12. Structure of the cation of $5 c$.

From 1d and 3-hexyne. Red-brown solid, yield 69\%. Eluent for chromatography: MeCN. Anal. calcd. for $\mathrm{C}_{28} \mathrm{H}_{30} \mathrm{~F}_{3} \mathrm{Fe}_{2} \mathrm{NO}_{5} \mathrm{~S}$ : $\mathrm{C}, 50.85 ; \mathrm{H}, 4.57 ; \mathrm{N}, 2.12 ; \mathrm{S}, 4.85$. Found: $\mathrm{C}$, $50.78 ; \mathrm{H}, 4.64 ; \mathrm{N}, 2.09 ; \mathrm{S}, 4.94$. IR $\left(\mathrm{CH}_{2} \mathrm{Cl}_{2}\right): \tilde{v} / \mathrm{cm}^{-1}=1986 \mathrm{vs}(\mathrm{CO}), 1804 \mathrm{~s}(\mu-\mathrm{CO}), 1649 \mathrm{~m}$ $\left(\mathrm{C}^{1}=\mathrm{N}\right) .{ }^{1} \mathrm{H}$ NMR $\left(\mathrm{CDCl}_{3}\right): \delta / \mathrm{ppm}=7.41-7.29,7.08(\mathrm{~m}, 5 \mathrm{H}, \mathrm{Ph}) ; 5.59,5.40,4.85,4.35$ $\left(\mathrm{d},{ }^{2} \mathrm{~J}_{\mathrm{HH}} \approx 14 \mathrm{~Hz}, 2 \mathrm{H}, \mathrm{NCH}_{2}\right) ; 5.28,5.02(\mathrm{~s}, 10 \mathrm{H}, \mathrm{Cp}) ; 4.19,4.09,2.53,2.28,2.07(\mathrm{br}, 4 \mathrm{H}$, $\left.\mathrm{CH}_{2} \mathrm{CH}_{3}\right) ; 3.69,2.90(\mathrm{~s}, 3 \mathrm{H}, \mathrm{NMe}) ; 1.95,1.72,1.44,1.28,1.14\left(\mathrm{br}, 6 \mathrm{H}, \mathrm{CH}_{2} \mathrm{CH}_{3}\right)$. Isomer ratio (trans-Z/cis-E) $=1.8 .{ }^{13} \mathrm{C}\left\{{ }^{1} \mathrm{H}\right\} \mathrm{NMR}\left(\mathrm{CDCl}_{3}\right): \delta / \mathrm{ppm}=258.9,257.8(\mu-\mathrm{CO}) ; 228.3,226.7$ $\left(C^{1}\right) ; 211.9,211.4(C O) ; 210.9,210.3\left(C^{3}\right) ; 132.4,131.3,129.4,129.3,129.2,129.1,128.9(\mathrm{Ph})$; 90.7, 90.5, 88.0, $87.8(\mathrm{Cp}) ; 68.5,61.8\left(\mathrm{NCH}_{2}\right) ; 66.9\left(\mathrm{C}^{2}\right) ; 46.4,42.1(\mathrm{NMe}) ; 43.2,42.9\left(\mathrm{C}^{3}-\mathrm{CH}_{2}\right)$; 24.1, $23.0\left(\mathrm{C}^{2}-\mathrm{CH}_{2}\right) ; 20.2,19.3,14.9,13.4\left(\mathrm{CH}_{2} \mathrm{CH}_{3}\right)$.

$\left[\mathrm{Fe}_{2} \mathrm{Cp}_{2}(\mathrm{CO})(\mu-\mathrm{CO})\left\{\mu-\eta^{1}: \eta^{3}-\mathrm{C}^{3}(\mathrm{Me}) \mathrm{C}^{2} \mathrm{HC}^{1} \mathrm{NMe}\left(4-\mathrm{C}_{6} \mathrm{H}_{4} \mathrm{OMe}\right)\right\}\right] \mathrm{CF}_{3} \mathrm{SO}_{3}, 6 \mathrm{a}$ (Scheme 13) [52]

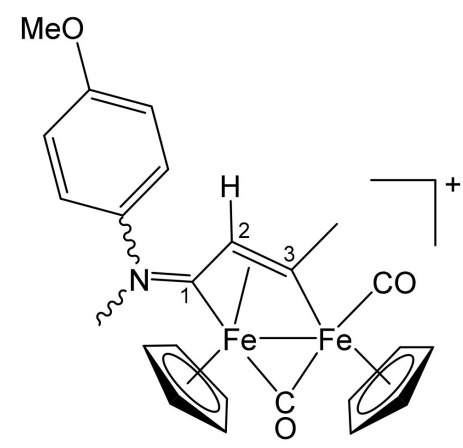

Scheme 13. Structure of the cation of 6 a. 
From 1e and propyne (THF solution, ca. $1 \mathrm{~mol} / \mathrm{L}$ ). Brown solid, yield 73\%. Eluent for chromatography: MeCN. Anal. calcd. for $\mathrm{C}_{25} \mathrm{H}_{24} \mathrm{~F}_{3} \mathrm{Fe}_{2} \mathrm{NO}_{6} \mathrm{~S}: \mathrm{C}, 47.27 ; \mathrm{H}, 3.81 ; \mathrm{N}, 2.21$; S, 5.05. Found: $\mathrm{C}, 47.13 ; \mathrm{H}, 3.91 ; \mathrm{N}, 2.13 ; \mathrm{S}, 5.09$. IR $\left(\mathrm{CH}_{2} \mathrm{Cl}_{2}\right): \tilde{v} / \mathrm{cm}^{-1}=1991 \mathrm{vs}(\mathrm{CO})$, 1811s $(\mu-\mathrm{CO}), 1642 \mathrm{~m}\left(\mathrm{C}^{1}=\mathrm{N}\right) .{ }^{1} \mathrm{H}$ NMR $\left(\right.$ acetone $\left.\mathrm{d}_{6}\right): \delta / \mathrm{ppm}=7.64,7.24,7.20,6.90(\mathrm{~m}$, $\left.4 \mathrm{H}, \mathrm{C}_{6} \mathrm{H}_{4}\right) ; 5.60,5.55,5.32,4.99(\mathrm{~s}, 10 \mathrm{H}, \mathrm{Cp}) ; 4.85,4.72\left(\mathrm{~s}, 1 \mathrm{H}, \mathrm{C}^{2} \mathrm{H}\right) ; 4.41,3.69(\mathrm{~s}, 3 \mathrm{H}$, $\mathrm{NMe}) ; 4.02,3.95\left(\mathrm{~s}, 3 \mathrm{H}, \mathrm{C}^{3} \mathrm{Me}\right) ; 3.81(\mathrm{~s}, 3 \mathrm{H}, \mathrm{OMe})$. Isomer ratio $(\mathrm{E} / \mathrm{Z})=2 .{ }^{13} \mathrm{C}\left\{{ }^{1} \mathrm{H}\right\} \mathrm{NMR}$ (acetone- $\left.\mathrm{d}_{6}\right): \delta / \mathrm{ppm}=255.6,254.8(\mu-\mathrm{CO}) ; 230.4,229.0\left(\mathrm{C}^{1}\right) ; 210.7,210.4(\mathrm{CO}) ; 209.5,208.8$ $\left(\mathrm{C}^{3}\right) ; 160.3$, 159.8 (ipso- $\left.\mathrm{C}_{6} \mathrm{H}_{4}\right) ; 139.4,136.5,126.1,122.8,114.6,114.3\left(\mathrm{C}_{6} \mathrm{H}_{4}\right) ; 91.0,88.1,87.8$

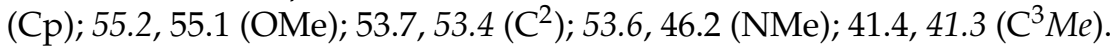

$\left[\mathrm{Fe}_{2} \mathrm{Cp}_{2}(\mathrm{CO})(\mu-\mathrm{CO})\left\{\mu-\eta^{1}: \eta^{3}-\mathrm{C}^{3}(\mathrm{Ph}) \mathrm{C}^{2} \mathrm{HC}^{1} \mathrm{NMe}\left(4-\mathrm{C}_{6} \mathrm{H}_{4} \mathrm{OMe}\right)\right\}\right] \mathrm{CF}_{3} \mathrm{SO}_{3}, 6 \mathrm{~b}$ (Scheme 14)

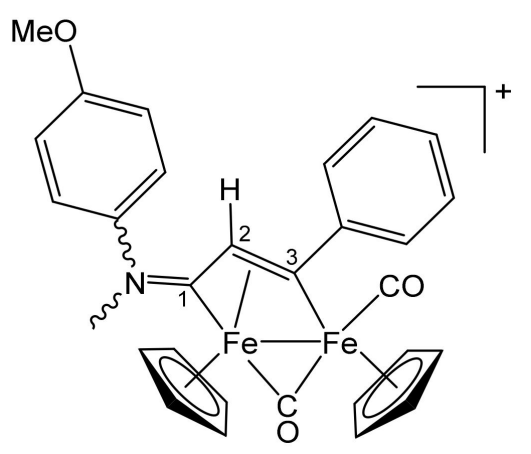

Scheme 14. Structure of the cation of $6 \mathbf{b}$.

From 1e and phenylacetylene. Brown solid, yield 71\%. Eluent for chromatography: MeCN. Anal. calcd. for $\mathrm{C}_{30} \mathrm{H}_{26} \mathrm{~F}_{3} \mathrm{Fe}_{2} \mathrm{NO}_{6} \mathrm{~S}$ : $\mathrm{C}, 51.68 ; \mathrm{H}, 3.76 ; \mathrm{N}, 2.01 ; \mathrm{S}, 4.60$. Found: $\mathrm{C}, 51.55 ; \mathrm{H}, 3.88 ; \mathrm{N}, 2.06 ; \mathrm{S}, 4.71$. IR $\left(\mathrm{CH}_{2} \mathrm{Cl}_{2}\right): \tilde{v} / \mathrm{cm}^{-1}=1994 \mathrm{vs}(\mathrm{CO}), 1814 \mathrm{~s}(\mu-\mathrm{CO})$, $1639 \mathrm{~m}\left(\mathrm{C}^{1}=\mathrm{N}\right) .{ }^{1} \mathrm{H}$ NMR $\left(\right.$ acetone- $\left.\mathrm{d}_{6}\right): \delta / \mathrm{ppm}=7.84,7.68,7.56,7.43,7.28,6.98(\mathrm{~m}$, $\left.9 \mathrm{H}, \mathrm{Ph}+\mathrm{C}_{6} \mathrm{H}_{4}\right) ; 5.57,5.33,5.27,5.18(\mathrm{~s}, 10 \mathrm{H}, \mathrm{Cp}) ; 4.93,4.72\left(\mathrm{~s}, 1 \mathrm{H}, \mathrm{C}^{2} \mathrm{H}\right) ; 4.51,3.80(\mathrm{~s}$, $3 \mathrm{H}, \mathrm{NMe}) ; 3.99,3.83(\mathrm{~s}, 3 \mathrm{H}, \mathrm{OMe})$. Isomer ratio $(\mathrm{E} / \mathrm{Z})=4 .{ }^{13} \mathrm{C}\left\{{ }^{1} \mathrm{H}\right\} \mathrm{NMR}$ (acetone- $\left.\mathrm{d}_{6}\right)$ : $\delta / \mathrm{ppm}=254.7(\mu-\mathrm{CO}) ; 229.2\left(\mathrm{C}^{1}\right) ; 210.0(\mathrm{CO}) ; 204.9\left(\mathrm{C}^{3}\right) ; 159.9\left(\right.$ ipso- $\left.\mathrm{C}_{6} \mathrm{H}_{4}\right) ; 156.4$ (ipso-Ph); $128.8,128.4,127.2,127.0,126.9,126.5,122.7,114.7,114.4\left(\mathrm{Ph}+\mathrm{C}_{6} \mathrm{H}_{4}\right) ; 92.0,91.9,88.3,87.9$

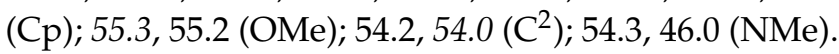

$\left[\mathrm{Fe}_{2} \mathrm{Cp}_{2}(\mathrm{CO})(\mu-\mathrm{CO})\left\{\mu-\eta^{1}: \eta^{3}-\mathrm{C}^{3}(\mathrm{Me}) \mathrm{C}^{2}(\mathrm{Me}) \mathrm{C}^{1} \mathrm{NMe}\left(4-\mathrm{C}_{6} \mathrm{H}_{4} \mathrm{OMe}\right)\right\}\right] \mathrm{CF}_{3} \mathrm{SO}_{3}, 6 \mathrm{c}$ (Scheme 15)

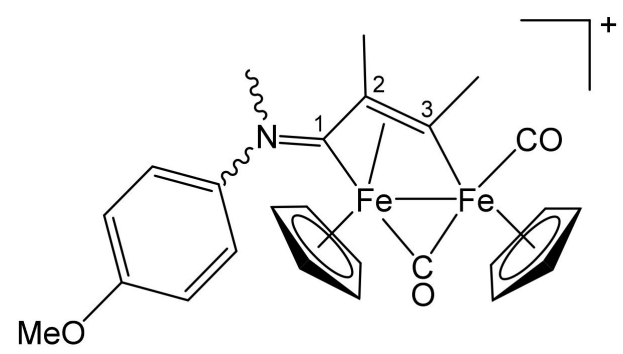

Scheme 15. Structure of the cation of $6 c$.

From 1e and 2-butyne. Brown solid, yield 83\%. Eluent for chromatography: MeCN. Anal. calcd. for $\mathrm{C}_{30} \mathrm{H}_{26} \mathrm{~F}_{3} \mathrm{Fe}_{2} \mathrm{NO}_{6} \mathrm{~S}$ : C, 51.68; H, 3.76; N, 2.01; S, 4.60. Found: C, 51.55; H, $3.88 ; \mathrm{N}, 2.06 ; \mathrm{S}, 4.71$. IR $\left(\mathrm{CH}_{2} \mathrm{Cl}_{2}\right): \tilde{v} / \mathrm{cm}^{-1}=1986 \mathrm{vs}(\mathrm{CO}), 1810 \mathrm{~s}(\mu-\mathrm{CO}), 1626 \mathrm{~m}\left(\mathrm{C}^{1}=\mathrm{N}\right)$. ${ }^{1} \mathrm{H}$ NMR (acetone- $\left.\mathrm{d}_{6}\right): \delta / \mathrm{ppm}=7.59,7.20,7.10,6.92\left(\mathrm{~m}, 4 \mathrm{H}, \mathrm{C}_{6} \mathrm{H}_{4}\right) ; 5.57,5.45,5.25,4.96(\mathrm{~s}$, $10 \mathrm{H}, \mathrm{Cp}) ; 4.44,3.56$ (s, $3 \mathrm{H}, \mathrm{NMe}) ; 3.93,3.78$ (s, $3 \mathrm{H}, \mathrm{OMe}) ; 3.89,3.82\left(\mathrm{~s}, 3 \mathrm{H}, \mathrm{C}^{3} \mathrm{Me}\right) ; 2.26$, $1.50\left(\mathrm{~s}, 3 \mathrm{H}, \mathrm{C}^{2} \mathrm{Me}\right)$. Isomer ratio $(\mathrm{Z} / \mathrm{E})=2.2 \cdot{ }^{13} \mathrm{C}\left\{{ }^{1} \mathrm{H}\right\} \mathrm{NMR}\left(\right.$ acetone- $\left._{6}\right): \delta / \mathrm{ppm}=257.3$, 255.4 ( $\mu$-CO); 229.9, 229.1 ( $\left.\mathrm{C}^{1}\right)$; 212.3, $211.8(\mathrm{CO}) ; 204.2$, $203.6\left(\mathrm{C}^{3}\right)$; 161.3, 160.7 (ipso- $\mathrm{C}_{6} \mathrm{H}_{4}$ ); 138.4, 138.2; 127.7, 123.0, 115.4, $115.1\left(\mathrm{C}_{6} \mathrm{H}_{4}\right) ; 92.5,92.2$, 89.6, 89.2 (Cp); 67.8, $67.2\left(\mathrm{C}^{2}\right) ; 56.2$, 56.1 (OMe); 52.7, 46.5 (NMe); 37.9, 37.2 ( $\left.\mathrm{C}^{3} \mathrm{Me}\right) ; 15.8,15.3\left(\mathrm{C}^{2} \mathrm{Me}\right)$. 


\section{$\left[\mathrm{Fe}_{2} \mathrm{Cp}_{2}(\mathrm{CO})(\mu-\mathrm{CO})\left\{\mu-\eta^{1}: \eta^{3}-\mathrm{C}^{3}(\mathrm{Me}) \mathrm{C}^{2}(\mathrm{Me}) \mathrm{C}^{1} \mathrm{NMe}(2-\right.\right.$-naphthyl) $\left.\}\right] \mathrm{CF}_{3} \mathrm{SO}_{3}, 7$ (Scheme 16)}

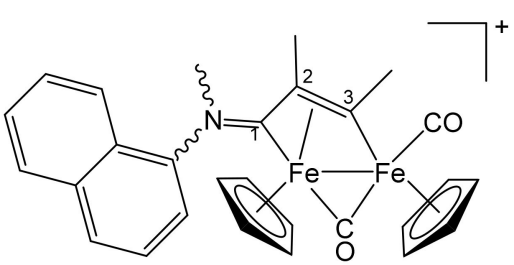

Scheme 16. Structure of the cation of 7.

From 1f and 2-butyne. Brown-red solid, yield 90\%. Eluent for chromatography: MeCN. Anal. calcd. for $\mathrm{C}_{29} \mathrm{H}_{26} \mathrm{~F}_{3} \mathrm{Fe}_{2} \mathrm{NO}_{5} \mathrm{~S}$ : C, 52.04; $\mathrm{H}, 3.92 ; \mathrm{N}, 2.09 ; \mathrm{S}, 4.79$. Found: $\mathrm{C}$, $51.89 ; \mathrm{H}, 3.99 ; \mathrm{N}, 2.01 ; \mathrm{S}, 4.94$. IR $\left(\mathrm{CH}_{2} \mathrm{Cl}_{2}\right): \tilde{v} / \mathrm{cm}^{-1}=1987 \mathrm{vs}(\mathrm{CO}), 1811 \mathrm{~s}(\mu-\mathrm{CO}), 1637 \mathrm{~m}$ $\left(\mathrm{C}^{1}=\mathrm{N}\right), 1616 \mathrm{w}-\mathrm{m}(\operatorname{arom} \mathrm{C}=\mathrm{C}) .{ }^{1} \mathrm{H}$ NMR $\left(\right.$ acetone- $\left.\mathrm{d}_{6}\right): \delta / \mathrm{ppm}=8.32-7.61,7.28(\mathrm{~m}, 7 \mathrm{H}$, arom $\mathrm{CH}) ; 5.67,5.51,5.36,5.01$ (s, $10 \mathrm{H}, \mathrm{Cp}) ; 4.67,3.75$ (s, $3 \mathrm{H}, \mathrm{NMe}) ; 3.97,3.93$ (s, $3 \mathrm{H}$, $\left.\mathrm{C}^{3} \mathrm{Me}\right) ; 2.26,1.55\left(\mathrm{~s}, 3 \mathrm{H}, \mathrm{C}^{2} \mathrm{Me}\right)$. Isomer ratio $(\mathrm{Z} / \mathrm{E})=1.5 .{ }^{13} \mathrm{C}\left\{{ }^{1} \mathrm{H}\right\} \mathrm{NMR}$ (acetone- $\left.\mathrm{d}_{6}\right)$ : $\delta / \mathrm{ppm}=256.0,254.5$ ( $\mu$-CO); $230.9\left(\mathrm{C}^{1}\right) ; 211.4(\mathrm{CO}) ; 203.9\left(\mathrm{C}^{3}\right) ; 141.0$ (ipso-Naph); 133.4, 132.7, 132.6, 129.7, 129.4, 128.5, 128.4, 128.1, 127.7, 127.5, 124.6, 122.8, 118.9 (arom CH); 91.7, 91.3, 88.9, 88.3 (Cp); $67.1\left(\mathrm{C}^{2}\right)$; 51.4, 45.6 (NMe); 37.1, 36.4 ( $\left.\mathrm{C}^{3} \mathrm{Me}\right)$; 15.0, $14.5\left(\mathrm{C}^{2} \mathrm{Me}\right)$.

\subsection{X-ray Crystallography}

Crystal data and collection details for $\mathbf{2} \mathbf{c}$ and $\mathbf{3 a}$ are reported in Table 1 . The data were recorded on a Bruker APEX II diffractometer equipped with a PHOTON100 detector using $\mathrm{Mo}-\mathrm{K} \alpha$ radiation. The data were corrected for Lorentz polarization and absorption effects (empirical absorption correction SADABS) [54]. The structures were solved by direct methods and refined by full-matrix least-squares based on all data using $F^{2}$ [55]. Hydrogen atoms were fixed at calculated positions and refined by a riding model. All non-hydrogen atoms were refined with anisotropic displacement parameters. The crystals of $\mathbf{2 c}$ appeared to be non-merohedrally twinned. The TwinRotMat routine of PLATON [56] was used to determine the twinning matrix and to write the reflection data file (.hkl) containing the twin components. Refinement was performed using the instruction HKLF 5 in SHELXL and one BASF parameter, which refined as 0.213 (5). Moreover, the whole molecule $2 \mathrm{c}$ is disordered and, therefore, it has been split into two positions and refined anisotropically employing one occupancy factor per disordered group. Because of this twinning and high disorder, several restraints were used during the refinement. The details are included in the CIF file. Therefore, even if the connectivity and overall geometry of $2 \mathrm{c}$ are certain, bonding distances and angles must be taken with care.

Table 1. Crystal data and measurement details for $\mathbf{2 c}$ and $\mathbf{3 a}$.

\begin{tabular}{ccc}
\hline & $2 \mathrm{c}$ & 3a \\
\hline Formula & $\mathrm{C}_{32} \mathrm{H}_{30} \mathrm{~F}_{3} \mathrm{Fe}_{2} \mathrm{NO}_{5} \mathrm{~S}$ & $\mathrm{C}_{21} \mathrm{H}_{22} \mathrm{~F}_{3} \mathrm{Fe}_{2} \mathrm{NO}_{5} \mathrm{~S}$ \\
$\mathrm{FW}$ & 709.33 & 569.15 \\
$\mathrm{~T}, \mathrm{~K}$ & $100(2)$ & $100(2)$ \\
$\lambda, \AA$ & 0.71073 & 0.71073 \\
Crystal system & Monoclinic & Monoclinic \\
Space group & $P 2_{1} / c$ & $P{ }_{1} / c$ \\
$a, \AA$ & $17.2348(14)$ & $9.9306(6)$ \\
$b, \AA$ & $8.9679(7)$ & $12.5791(7)$ \\
$c^{\circ} \AA$ & $19.8255(14)$ & $17.5345(10)$ \\
$\beta$, & $104.380(3)$ & $90.604(2)$ \\
Cell volume, $\AA^{3}$ & $2968.2(4)$ & $2190.3(2)$ \\
$\mathrm{Z}$ & 4 & 4 \\
$D_{c}, \mathrm{~g}^{\circ} \mathrm{cm}^{-3}$ & 1.587 & 1.726 \\
$\mu, \mathrm{mm}^{-1}$ & 1.110 & 1.480 \\
\hline
\end{tabular}


Table 1. Cont.

\begin{tabular}{ccc}
\hline & 2c & 3a \\
\hline $\mathrm{F}(000)$ & 1456 & 1160 \\
Crystal size, mm & $0.18 \times 0.15 \times 0.11$ & $0.21 \times 0.18 \times 0.13$ \\
$\theta$ limits, & ${ }^{\circ}$ & $1.993-25.994$ \\
Reflections collected & $2.121-25.081$ & 39,294 \\
Independent reflections & 28,217 & $4267\left[R_{\text {int }}=0.1414\right]$ \\
Data/restraints/parameters & $5184\left[R_{\text {int }}=0.0817\right]$ & $4267 / 0 / 300$ \\
Goodness on fit on $\mathrm{F}^{2}$ & $5184 / 1041 / 513$ & 1.142 \\
$R_{1}(I>2 \sigma(I))$ & 1.283 & 0.0480 \\
$w R_{2}($ all data) & 0.1207 & 0.0964 \\
$\mathrm{~A}^{-3}$ & 0.2512 & $0.607 /-0.504$ \\
\hline
\end{tabular}

2.4. Solubility and Stability in Water and Determination of Octanol-Water Partition Coefficients

(a) Solubility in $\mathrm{D}_{2} \mathrm{O}$. A suspension of the selected diiron compound (3-5 mg) in a $\mathrm{D}_{2} \mathrm{O}$ solution (ca. $1 \mathrm{~mL}$ ) containing $\mathrm{Me}_{2} \mathrm{SO}_{2}\left(3.36 \times 10^{-3} \mathrm{M}\right)$ as internal standard [57] was vigorously stirred at $21{ }^{\circ} \mathrm{C}$ for $1.5 \mathrm{~h}$. The resulting saturated solution was filtered over celite, transferred into an NMR tube and then analyzed by ${ }^{1} \mathrm{H}$ NMR spectroscopy (delay time $=3 \mathrm{~s}$; number of scans $=20$ ). The concentration (solubility) was calculated by the relative integral (related to $\mathrm{Cp}$ and/or NMe signals) with respect to $\mathrm{Me}_{2} \mathrm{SO}_{2}$ $(\delta=3.14 \mathrm{ppm})$.

(b) Stability in DMSO- $\mathrm{d}_{6} / \mathrm{D}_{2} \mathrm{O}$ solution. The selected diiron compound (ca. $4 \mathrm{mg}$ ) was added of $1 \mathrm{~mL}$ of $\mathrm{D}_{2} \mathrm{O}(\mathbf{3 a}, \mathbf{c})$ or DMSO- $\mathrm{d}_{6} / \mathrm{D}_{2} \mathrm{O}(2: 1 \mathrm{v} / \mathrm{v})$ mixture $(\mathbf{2} \mathbf{a}, \mathbf{c}, \mathbf{3} \mathbf{b}, \mathbf{4 a - c}, \mathbf{5} \mathbf{a}-\mathbf{c}$, $6 \mathrm{a}-\mathrm{c}, 7)$, containing $\mathrm{Me}_{2} \mathrm{SO}_{2}\left(3.36 \times 10^{-3} \mathrm{M}\right)$. The resulting mixture was stirred for $30 \mathrm{~min}$ and then filtered over celite; the filtrated solution was transferred into an NMR tube. The sample was analyzed by ${ }^{1} \mathrm{H}$ NMR (time $\left.=0\right)$ and then heated at $37^{\circ} \mathrm{C}$ for $72 \mathrm{~h}$. After cooling to room temperature, the solution was separated from a small amount of solid by filtration over celite, and the new ${ }^{1} \mathrm{H}$ NMR spectrum was recorded (delay time $=3 \mathrm{~s}$; number of scans $=20$ ). In every case, no newly formed organometallic species was detected. The amount of starting material in solution (\% with respect to the initial spectrum) was calculated by the relative integral (vs. Cp and/or NMe signals) with respect to $\mathrm{Me}_{2} \mathrm{SO}_{2}$ as internal standard. Data related to the spectra recorded at time $=0$ are reported in the following.

2a. ${ }^{1} \mathrm{H}$ NMR $\left(\mathrm{D}_{2} \mathrm{O} /\right.$ DMSO-d $_{6}$ 2:1): $\delta / \mathrm{ppm}=7.43,7.15,6.99(\mathrm{~m}, 10 \mathrm{H}, \mathrm{Ph}) ; 5.83,5.14(\mathrm{~d}$, $\left.2 \mathrm{H}, \mathrm{CH}_{2}\right) ; 5.48,5.08$ (s, $\left.10 \mathrm{H}, \mathrm{Cp}\right) ; 4.54,4.27\left(\mathrm{~d}, 2 \mathrm{H}, \mathrm{CH}_{2}\right) ; 3.87\left(\mathrm{~s}, 3 \mathrm{H}, \mathrm{C}^{3} \mathrm{Me}\right)$.

2c. ${ }^{1} \mathrm{H}$ NMR $\left(\mathrm{D}_{2} \mathrm{O} / \mathrm{DMSO}_{6} \mathrm{~d}_{6}\right.$ 2:1): $\delta / \mathrm{ppm}=7.4-6.9(\mathrm{~m}, 10 \mathrm{H}, \mathrm{Ph}) ; 4.73\left(\mathrm{~d}, 1 \mathrm{H}, \mathrm{CH}_{2}\right)$; 5.42, 5.01 (s, $10 \mathrm{H}, \mathrm{Cp}) ; 3.82\left(\mathrm{~s}, 3 \mathrm{H}, \mathrm{C}^{3} \mathrm{Me}\right) ; 2.17$ (s, $\left.3 \mathrm{H}, \mathrm{C}^{2} \mathrm{Me}\right)$.

3a. ${ }^{1} \mathrm{H}$ NMR $\left(\mathrm{D}_{2} \mathrm{O}\right): \delta / \mathrm{ppm}=5.92-5.82,5.62-5.54,5.38-5.33\left(\mathrm{~m}, \mathrm{CH}=\mathrm{CH}_{2}\right) ; 5.29,5.29$, 4.92, $4.90(\mathrm{~s}, \mathrm{Cp}) ; 3.68,3.67\left(\mathrm{~s}, \mathrm{C}^{3} \mathrm{Me}\right)$; 3.65, 3.01 (NMe). Isomer ratio $=1.1$.

3b. ${ }^{1} \mathrm{H}$ NMR $\left(\mathrm{D}_{2} \mathrm{O} / \mathrm{DMSO}_{6} \mathrm{~d}_{6}\right.$ 2:1): $\delta / \mathrm{ppm}=7.73,7.59,7.47(\mathrm{~m}, 5 \mathrm{H}, \mathrm{Ph}) ; 5.97(\mathrm{br}$, $\left.\mathrm{CH}=\mathrm{CH}_{2}\right) ; 5.65,5.54,5.35,5.31\left(\mathrm{~m}, \mathrm{CH}=\mathrm{CH}_{2}\right) ; 5.27,5.25,5.15(\mathrm{~s}, 10 \mathrm{H}, \mathrm{Cp}) ; 4.12(\mathrm{~m}$, $\left.\mathrm{NCH}_{2}\right) ; 3.85,3.23(\mathrm{~s}, 3 \mathrm{H}, \mathrm{NMe})$. Isomer ratio $=1.5$.

3c. ${ }^{1} \mathrm{H}$ NMR $\left(\mathrm{D}_{2} \mathrm{O}\right): \delta / \mathrm{ppm}=5.99,5.62,5.52,5.36\left(\mathrm{~m}, \mathrm{CH}=\mathrm{CH}_{2}\right) ; 5.26,5.24,4.92,4.90$ (s, Cp); 3.68, 3.65, 3.05 (s, $\left.\mathrm{C}^{3} \mathrm{Me}+\mathrm{NMe}\right) ; 2.04\left(\mathrm{~s}, \mathrm{C}^{2} \mathrm{Me}\right)$.

4a. ${ }^{1} \mathrm{H}$ NMR $\left(\mathrm{D}_{2} \mathrm{O} / \mathrm{DMSO}^{\mathrm{d}} \mathrm{d}_{6} 2: 1\right): \delta / \mathrm{ppm}=5.35,5.34,5.17,4.97(\mathrm{~s}, 10 \mathrm{H}, \mathrm{Cp}) ; 3.77$, $3.75\left(\mathrm{~s}, 3 \mathrm{H}, \mathrm{C}^{3} \mathrm{Me}\right) ; 3.73,3.00(\mathrm{~s}, 3 \mathrm{H}, \mathrm{NMe}) ; 3.43\left(\mathrm{~m}, 1 \mathrm{H}, \mathrm{CH}^{\mathrm{Cy}}\right) ; 2.08-0.85\left(\mathrm{~m}, 10 \mathrm{H}, \mathrm{CH}_{2}{ }^{\mathrm{Cy}}\right)$. Isomer ratio $=1.9$.

4c. ${ }^{1} \mathrm{H}$ NMR $\left(\mathrm{D}_{2} \mathrm{O} / \mathrm{DMSO}^{\mathrm{d}} \mathrm{d}_{6} 2: 1\right): \delta / \mathrm{ppm}=5.35,5.34,5.01,4.97(\mathrm{~s}, 10 \mathrm{H}, \mathrm{Cp}) ; 3.77$, 3.75, $3.73\left(\mathrm{~s}, \mathrm{NMe}+\mathrm{C}^{3} \mathrm{Me}\right) ; 2.1,1.8-1.1\left(\mathrm{~m}, 10 \mathrm{H}, \mathrm{CH}_{2}{ }^{\mathrm{Cy}}\right) ; 1.87,1.85\left(\mathrm{~s}, 3 \mathrm{H}, \mathrm{C}^{2} \mathrm{Me}\right)$. Isomer ratio $=1.8$.

5a. ${ }^{1} \mathrm{H}$ NMR $\left(\mathrm{D}_{2} \mathrm{O} / \mathrm{DMSO}_{6} \mathrm{~d}_{6}\right.$ 2:1): $\delta / \mathrm{ppm}=7.48,7.36,7.21(\mathrm{~m}, 5 \mathrm{H}, \mathrm{Ph}) ; 5.45,5.43$, $5.07(\mathrm{~s}, 10 \mathrm{H}, \mathrm{Cp}) ; 3.88\left(\mathrm{~s}, 3 \mathrm{H}, \mathrm{C}^{3} \mathrm{Me}\right) ; 3.61,3.03(\mathrm{~s}, 3 \mathrm{H}, \mathrm{NMe})$. Isomer ratio = 1.2. 
5b. ${ }^{1} \mathrm{H}$ NMR $\left(\mathrm{D}_{2} \mathrm{O} / \mathrm{DMSO}_{6} \mathrm{~d}_{6}\right.$ 2:1): $\delta / \mathrm{ppm}=7.49-7.36,7.19(\mathrm{~m}, 5 \mathrm{H}, \mathrm{Ph}) ;$ 5.40, 5.39, 5.06, 5.01 (s, $10 \mathrm{H}, \mathrm{Cp}) ; 4.50\left(\mathrm{~d}, 1 \mathrm{H}, \mathrm{CH}_{2}\right)$; 3.79 (s, $\left.3 \mathrm{H}, \mathrm{C}^{3} \mathrm{Me}\right)$; 3.65, 3.06 (s, $\left.3 \mathrm{H}, \mathrm{NMe}\right) ; 1.94$, $1.91\left(\mathrm{C}^{2} \mathrm{Me}\right)$. Isomer ratio $=1.7$.

5c. ${ }^{1} \mathrm{H}$ NMR $\left(\mathrm{D}_{2} \mathrm{O} / \mathrm{DMSO}-\mathrm{d}_{6}\right.$ 2:1): $\delta / \mathrm{ppm}=7.51,7.43,7.14(\mathrm{~m}, 5 \mathrm{H}, \mathrm{Ph}) ; 5.53,5.30,4.51$ (d, $\left.2 \mathrm{H}, \mathrm{NCH}_{2}\right) ; 5.42,5.40,5.12,5.09$ (s, $\left.10 \mathrm{H}, \mathrm{Cp}\right) ; 4.18,4.13,2.46,2.13$ (br, $4 \mathrm{H}, \mathrm{CH}_{2} \mathrm{CH}_{3}$ ); $3.72,2.94$ (s, NMe); 2.11, 1.69, 1.13, $0.98\left(\mathrm{br}, \mathrm{CH}_{2} \mathrm{CH}_{3}\right)$. Isomer ratio = 1.7 .

6a. ${ }^{1} \mathrm{H}$ NMR $\left(\mathrm{D}_{2} \mathrm{O} / \mathrm{DMSO}_{6} \mathrm{~d}_{6} 2: 1\right): \delta / \mathrm{ppm}=7.52,7.21,7.10,6.93\left(\mathrm{~m}, 4 \mathrm{H}, \mathrm{C}_{6} \mathrm{H}_{4}\right) ; 5.43$, 5.37, 5.14, 4.85 (s, $10 \mathrm{H}, \mathrm{Cp}) ; 4.63$ (s, $\left.1 \mathrm{H}, \mathrm{C}^{2} \mathrm{H}\right)$; 4.41, 3.69 (s, $\left.3 \mathrm{H}, \mathrm{NMe}\right) ; 4.23,3.93$ (s, $3 \mathrm{H}$, $\left.\mathrm{C}^{3} \mathrm{Me}\right) ; 3.87,3.79(\mathrm{~s}, 3 \mathrm{H}, \mathrm{OMe})$. Isomer ratio $=2$.

6b. ${ }^{1} \mathrm{H}$ NMR $\left(\mathrm{D}_{2} \mathrm{O} / \mathrm{DMSO}_{6} \mathrm{~d}_{6} 2: 1\right): \delta / \mathrm{ppm}=7.73,7.58,7.43,7.23,7.16,6.98(\mathrm{~m}, 9 \mathrm{H}$, $\left.\mathrm{Ph}+\mathrm{C}_{6} \mathrm{H}_{4}\right) ; 5.37,5.19,5.12,5.03(\mathrm{~s}, 10 \mathrm{H}, \mathrm{Cp}) ; 4.32,3.96$ (s, $\left.3 \mathrm{H}, \mathrm{NMe}\right) ; 3.79,3.64(\mathrm{~s}, 3 \mathrm{H}$, $\mathrm{OMe})$. Isomer ratio $=3$.

6c. ${ }^{1} \mathrm{H}$ NMR $\left(\mathrm{D}_{2} \mathrm{O} / \mathrm{DMSO}_{6} \mathrm{~d}_{6}\right.$ 2:1): $\delta / \mathrm{ppm}=7.94,7.21,7.04,6.94\left(\mathrm{~m}, 4 \mathrm{H}, \mathrm{C}_{6} \mathrm{H}_{4}\right) ; 5.45$, 5.32, 5.10, 4.84 (s, $10 \mathrm{H}, \mathrm{Cp}) ; 4.30,3.46$ (s, $3 \mathrm{H}, \mathrm{NMe}) ; 3.93,3.78$ (s, $3 \mathrm{H}, \mathrm{OMe}) ; 3.74$ (s, $3 \mathrm{H}$, $\left.\mathrm{C}^{3} \mathrm{Me}\right) ; 2.00,1.44\left(\mathrm{~s}, 3 \mathrm{H}, \mathrm{C}^{2} \mathrm{Me}\right)$. Isomer ratio $=2.3$.

7. ${ }^{1} \mathrm{H}$ NMR $\left(\mathrm{D}_{2} \mathrm{O} / \mathrm{DMSO}_{6} \mathrm{~d}_{6}\right.$ 2:1): $\delta / \mathrm{ppm}=8.23-7.21(\mathrm{~m}, 7 \mathrm{H}$, arom CH$) ; 5.51,5.34$, 5.16, 4.86 (s, $10 \mathrm{H}, \mathrm{Cp}) ; 4.47,3.61$ (s, $3 \mathrm{H}, \mathrm{NMe}) ; 3.82,3.78$ (s, $\left.3 \mathrm{H}, \mathrm{C}^{3} \mathrm{Me}\right) ; 2.09,1.44$ (s, $3 \mathrm{H}$, $\left.\mathrm{C}^{2} \mathrm{Me}\right)$. Isomer ratio $=2$.

(c) Octanol-water partition coefficients $\left(\log P_{\mathrm{ow}}\right)$. Partition coefficients $\left(P_{\mathrm{ow}} ; \mathrm{IUPAC}: K_{\mathrm{D}}\right.$ partition constant [58]), defined as $P_{\mathrm{ow}}=\mathrm{c}_{\mathrm{org}} / \mathrm{c}_{\mathrm{aq}}$, where $\mathrm{c}_{\mathrm{org}}$ and $\mathrm{c}_{\mathrm{aq}}$ are molar concentrations of the selected compound in the organic and aqueous phase, respectively, were determined by the shake-flask method and UV-Vis measurements $[36,59,60]$. Deionized water and 1-octanol were vigorously stirred for $24 \mathrm{~h}$ to enable saturation of both phases, then separated by centrifugation. A stock solution of the selected diiron compound ( $c a .2 \mathrm{mg} ; \mathbf{2 a}-\mathbf{c}, \mathbf{3 b}, \mathbf{4 a}-\mathbf{c}, \mathbf{5 a}, \mathbf{5 c}, \mathbf{6 b}, \mathbf{c}, \mathbf{7}$ ) was prepared by first adding acetone $(50 \mu \mathrm{L}$, to help solubilization), followed by water-saturated octanol $(2.5 \mathrm{~mL})$. The solution was diluted with water-saturated octanol (ca. 1:3 v/v ratio, $\mathrm{C}_{\mathrm{Fe} 2} \approx 10^{-4} \mathrm{M}$, so that $1.5 \leq \mathrm{A} \leq 2.0$ at $\left.\lambda_{\max }\right)$ and the $\mathrm{UV}-\mathrm{Vis}$ spectrum was recorded $\left(\mathrm{A}^{0}{ }_{\text {org }}\right)$. An aliquot of the solution $\left(\mathrm{V}_{\text {org }}=1.2 \mathrm{~mL}\right)$ was transferred into a test tube and octanol-saturated water $\left(\mathrm{V}_{\mathrm{org}}=\mathrm{V}_{\mathrm{aq}}=1.2 \mathrm{~mL}\right)$ was added. The mixture was vigorously stirred for $15 \mathrm{~min}$ at $21{ }^{\circ} \mathrm{C}$ and then centrifuged (5000 rpm, $10 \mathrm{~min}$ ). The UV-Vis spectrum of the organic phase was recorded $\left(\mathrm{A}^{\mathrm{f}}{ }_{\text {org }}\right)$ and the partition coefficient was calculated as $P_{\text {ow }}=\mathrm{A}_{\text {org }}^{\mathrm{f}} /\left(\mathrm{A}^{0}\right.$ org $\left.-\mathrm{A}_{\text {org }}^{\mathrm{f}}\right)$, where $\mathrm{A}^{0}$ org and $\mathrm{A}_{\text {org }}^{\mathrm{f}}$ are the absorbance in the organic phase before and after partition with the aqueous phase, respectively [59]. An inverse procedure was followed for $3 a, 3 c, 5 b$ and $6 a$, starting from a solution of the compound in octanol-saturated water. The partition coefficient was calculated as $P_{\text {ow }}=\left(\mathrm{A}^{0}\right.$ aq $\left.-\mathrm{A}_{\text {aq }}^{\mathrm{f}}\right) / \mathrm{A}^{\mathrm{f}}{ }_{\text {aq }}$ where $\mathrm{A}^{0}{ }_{\text {aq }}$ and $\mathrm{A}^{\mathrm{f}}{ }_{\text {aq }}$ are the absorbance in the aqueous phase before and after partition with the organic phase, respectively. The wavelength of the maximum absorption of each compound (ca. $300 \mathrm{~nm}$ ) was used for UV-Vis quantitation. The procedure was repeated three times for each sample (from the same stock solution); results are given as mean \pm standard deviation. Naphthoquinone was used as a reference compound $(\log P=1.8 \pm 0.2$; literature [61]: 1.71).

\subsection{Cell Culture and Cytotoxicity Studies}

In vitro cytotoxicity investigations were carried out by using human ovarian carcinoma cisplatin-sensitive A2780 (ECACC93112519), human ovarian carcinoma cisplatinresistant A2780cisR (ECACC 93112517) and mouse embryo fibroblasts Balb/3T3 clone A31 (ATCC CCL-163) cell lines. A2780 and A2780cisR were purchased from the European Collection of Authenticated Cell Cultures (ECACC), and Balb/3T3 clone A31 cell line from the American Type Culture Collection (ATCC).

A2780 and A2780cisR cells were routinely cultured in RPMI 1640 (Merck) containing $2 \mathrm{mM}$ of L-glutamine (Merck), $1 \%$ of penicillin/streptomycin solution (Merck-10000 $\mathrm{U} \mathrm{mL}^{-1}: 10 \mathrm{mg} \mathrm{mL}^{-1}$ ), $10 \%$ of fetal bovine serum (Merck-FBS) and antimycotic (InvivoGen, USA), and Balb/3T3 clone A31 in Dulbecco's modified Eagle medium (Merck-DMEM) supplemented with 
$4 \mathrm{mM}$ of L-glutamine, 1\% of penicillin/streptomycin solution, $10 \%$ of calf serum (Merck) and antimycotic. The acquired resistance of A2780cisR cells was maintained by routine supplementation of media with $1 \mu \mathrm{M}$ of cisplatin (Merck). The cultures were maintained at $37^{\circ} \mathrm{C}$ and in a $5 \% \mathrm{CO}_{2}$-enriched atmosphere.

A2780, A2780cisR and Balb/3T3 clone A31 cells were seeded in 96-well tissue culture polystyrene plates at a concentration of $3 \times 10^{3}, 6 \times 10^{3}$ and $1 \times 10^{3}$ cells per well, respectively. After overnight incubation, the cells were treated with different concentrations $(0-100 \mu \mathrm{M})$ of the selected compounds for $72 \mathrm{~h}$ at $37^{\circ} \mathrm{C}$ in a $5 \%$ atmosphere of $\mathrm{CO}_{2}$. Stock solutions of compounds were prepared in DMSO and sequentially diluted in medium (final DMSO concentration of $0.5 \%$ ). Cells incubated with cisplatin $(0-100 \mu \mathrm{M})$ were used as positive control. At the end of the incubation time, cell viability was assessed by means of WST-1 tetrazolium salt reagent (Roche). Briefly, cells were incubated for $4 \mathrm{~h}$ with the tetrazolium salt reagent diluted $1: 10$, at $37^{\circ} \mathrm{C}$ and $5 \% \mathrm{CO}_{2}$. Measurements of formazan dye absorbance, which directly correlates with the number of viable cells, were carried out with a micro-plate reader (Biorad) at $450 \mathrm{~nm}$, using $655 \mathrm{~nm}$ as reference wavelength. The 50\% inhibitory concentration $\left(\mathrm{IC}_{50}\right)$ refers to compound concentration at which $50 \%$ of cell death is observed with respect to the control. For each tested compound, assay was performed on triplicate. The concentration effect curves were generated by nonlinear regression curves (GraphPad Prism Software, 2021) and the data reported as mean \pm standard deviation.

\subsection{ROS Determination}

The intracellular production of reactive oxygen species (ROS) upon treatment of the compounds $3 b, 4 a, 4 c, 5 b$ and $6 c$ was measured by using the DCFH-DA $\left(2^{\prime}, 7^{\prime}\right.$ dichlorodihydrofluorescein diacetate, Merck) assay, based on cellular uptake of the nonfluorescent diacetate following deacetylation by esterases $\left(2^{\prime}, 7^{\prime}\right.$-dichlorodihydrofluorescein, $\mathrm{DCFH})$ and oxidation to the fluorescent dichlorofluorescein $\left(2^{\prime}, 7^{\prime}\right.$-dichlorofluorescein, DCF) [62]. A2780 cells were seeded at concentration of $4 \times 10^{4}$ cells $/$ well $/ 90 \mu \mathrm{L}$ of complete growth medium into 96-well plates. After overnight incubation, the cells were treated following manufacturer protocol. $100 \mu \mathrm{L}$ of a solution containing the fluorogenic probe were added to the culture medium and, after $1 \mathrm{~h}$ of incubation with $5 \% \mathrm{CO}_{2}$ at $37^{\circ} \mathrm{C}$, the cells were exposed to a final concentration of $20 \mu \mathrm{M}$ of the tested complexes; $\mathrm{H}_{2} \mathrm{O}_{2}$ $100 \mu \mathrm{M}$ was used as a positive control. Stock solutions of compounds were prepared as described above; cells incubated with equal amounts of DMSO in supplemented RPMI were used as control. The fluorescence was measured up to $24 \mathrm{~h}$ with an excitation wavelength of $485 \mathrm{~nm}$ and with a $535 \mathrm{~nm}$ emission filter by Multilabel Counter (PerkinElmer). For each tested compound, assay was performed on triplicate. The data were reported as mean \pm standard deviation, statistical differences were analyzed using one-way analysis of variance (ANOVA) and a Tukey test was used for post hoc analysis. A $p$-value $<0.05$ is considered statistically significant.

\subsection{Biomolecules Binding Studies}

(a) Sample preparation. Cytochrome c (Cyt c) was commercially available and used as received; the TrxR dodecapeptide (TrxR-pept) was synthesized as reported in the literature $[63,64]$. The stock solutions of the selected iron-based complexes were prepared in DMSO up to a final concentration of $10^{-2} \mathrm{M}$. The stock solution of TrxR-pept was prepared in LC-MS grade water by dissolving the required amount of lyophilized peptide to reach a final concentration of $10^{-3} \mathrm{M}$. The stock solution of Cyt c $10^{-3} \mathrm{M}$ was prepared by dissolving the required amount of protein in $2 \mathrm{mM}$ ammonium acetate solution at $\mathrm{pH}$ 6.8. In the interaction tests with TrxR-pept, opportune aliquots of each complex and TrxR-pept stock solutions were mixed and diluted with LC-MS grade water to $10^{-4} \mathrm{M}$ final concentration and a TrxR-pept/complex ratio of 1:1. For each iron-based complex/Cyt c pair, appropriate aliquots of the respective stock solutions were mixed and subsequently diluted with $2 \mathrm{mM}$ ammonium acetate solution ( $\mathrm{pH}$ 6.8) to a final protein concentration of $10^{-4} \mathrm{M}$ and a protein-to-metal molar ratio of 1:2. 
All the sample mixtures were incubated for $24 \mathrm{~h}$ at $37^{\circ} \mathrm{C}$. Subsequently, opportune dilutions were performed as detailed:

- the TrxR-pept containing solutions were further diluted with LC-MS grade water to a final TrxR-pept concentration of $10^{-5} \mathrm{M}$ and added with $0.1 \% v / v$ of formic acid just before infusion in the mass spectrometer;

- the protein-containing solutions were diluted with $2 \mathrm{mM}$ ammonium acetate solution ( $\mathrm{pH}$ 6.8) to a final protein concentration of $10^{-6} \mathrm{M}$ and added with $0.1 \%$ $v / v$ of formic acid just before infusion.

(b) ESI-MS instrumental parameters. The ESI mass spectra were acquired using a TripleTOF ${ }^{\circledR} 5600^{+}$high-resolution mass spectrometer (Sciex, Framingham, MA, USA), with a DuoSpray ${ }^{\circledR}$ interface operating with an ESI probe. Respective ESI mass spectra were acquired through direct infusion at $7 \mu \mathrm{L} \mathrm{min}^{-1}$ flow rate. The ESI source parameters were optimized for each biomolecule and were as follows: for TrxR dodecapeptide positive polarity, ionspray voltage floating $5500 \mathrm{~V}$, temperature 0 , ion source gas 1 (GS1) $35 \mathrm{~L} \mathrm{~min}^{-1}$; ion source gas 2 (GS2) 0; curtain gas (CUR) $20 \mathrm{~L} \mathrm{~min}^{-1}$, declustering potential (DP) $300 \mathrm{~V}$, collision energy (CE) $10 \mathrm{~V}$, range 1070-1600 m/z; for Cyt c positive polarity, ionspray voltage floating $5500 \mathrm{~V}$, temperature 0 , ion source gas 1 (GS1) $35 \mathrm{~L} \mathrm{~min}^{-1}$; ion source gas 2 (GS2) 0; curtain gas (CUR) $20 \mathrm{~L} \mathrm{~min}^{-1}$, declustering potential (DP) $180 \mathrm{~V}$, collision energy (CE) $10 \mathrm{~V}$, range 500-1800 m/z. For acquisition, Analyst TF software 1.7.1 (Sciex, Framingham, MA, USA) was used and deconvoluted spectra were obtained by using the Bio Tool Kit micro-application v.2.2 embedded in PeakView ${ }^{\mathrm{TM}}$ software v.2.2 (Sciex, Framingham, MA, USA).

\section{Results and Discussion}

\subsection{Synthesis and Structural Characterization of Diiron Complexes}

A series of diiron complexes with novel vinyliminium ligands, 2-7, was synthesized from the respective aminocarbyne precursors, $\mathbf{1 a}-\mathbf{f}$, by means of a two-step procedure (see Scheme 17 and Table 2). This consists of the preliminary CO-NCMe substitution promoted by trimethylamine-N-oxide, followed by replacement of the labile acetonitrile ligand with the appropriate alkyne in dichloromethane solution at room temperature. Three main alkynes were selected, i.e., propyne, phenylacetylene and 2-butyne, which previously demonstrated to provide enhanced cytotoxicity to other vinyliminium complexes (Figure 1) [39]. In addition, 3-hexyne was employed to build $\mathbf{5 c}$, in order to outline the possible effect of the length of alkyl chains (upon comparison with $5 \mathbf{b}$ ) [39]. Note that 1a-f are available from $\left[\mathrm{Fe}_{2} \mathrm{Cp}_{2}(\mathrm{CO})_{4}\right]$ in high yields via multigram scale synthesis [36,47].

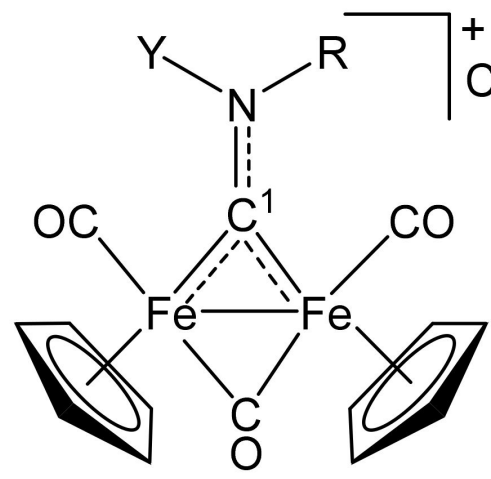

1a-f

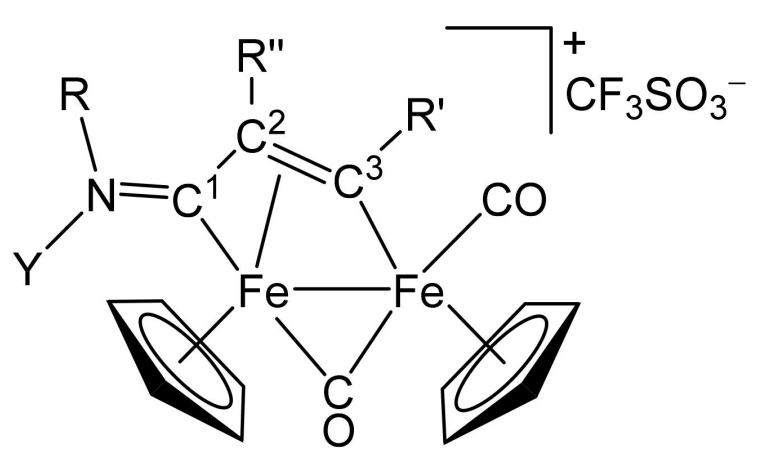

2-7

Scheme 17. General synthetic pathway to diiron vinyliminium complexes (see Table 2 for details). 
Table 2. Diiron vinyliminium complexes (2-7) obtained by aminocarbyne precursors (1a-f) according to Scheme 17.

\begin{tabular}{|c|c|c|c|c|c|}
\hline Precursor & $\mathbf{R}$ & $\mathbf{Y}$ & $\mathbf{R}^{\prime}$ & $\mathbf{R}^{\prime \prime}$ & Product \\
\hline $1 a$ & $\mathrm{CH}_{2} \mathrm{Ph}$ & $\mathrm{CH}_{2} \mathrm{Ph}$ & $\mathrm{Me}$ & $\mathrm{H}$ & $2 a$ \\
\hline 1a & $\mathrm{CH}_{2} \mathrm{Ph}$ & $\mathrm{CH}_{2} \mathrm{Ph}$ & $\mathrm{Ph}$ & $\mathrm{H}$ & $2 b$ \\
\hline $1 a$ & $\mathrm{CH}_{2} \mathrm{Ph}$ & $\mathrm{CH}_{2} \mathrm{Ph}$ & $\mathrm{Me}$ & $\mathrm{Me}$ & $2 c$ \\
\hline $1 b$ & $\mathrm{CH}_{2} \mathrm{CH}=\mathrm{CH}_{2}$ & $\mathrm{Me}$ & $\mathrm{Me}$ & $\mathrm{H}$ & $3 a$ \\
\hline $1 b$ & $\mathrm{CH}_{2} \mathrm{CH}=\mathrm{CH}_{2}$ & $\mathrm{Me}$ & $\mathrm{Ph}$ & $\mathrm{H}$ & $3 b$ \\
\hline $1 b$ & $\mathrm{CH}_{2} \mathrm{CH}=\mathrm{CH}_{2}$ & $\mathrm{Me}$ & $\mathrm{Me}$ & $\mathrm{Me}$ & $3 c$ \\
\hline 1c & $\mathrm{C}_{6} \mathrm{H}_{11}=\mathrm{Cy}$ & $\mathrm{Me}$ & $\mathrm{Me}$ & $\mathrm{H}$ & $4 a$ \\
\hline 1c & $\mathrm{Cy}$ & $\mathrm{Me}$ & $\mathrm{Ph}$ & $\mathrm{H}$ & $4 b$ \\
\hline 1c & Cy & $\mathrm{Me}$ & $\mathrm{Me}$ & $\mathrm{Me}$ & $4 c$ \\
\hline 1d & $\mathrm{CH}_{2} \mathrm{Ph}$ & $\mathrm{Me}$ & $\mathrm{Me}$ & $\mathrm{H}$ & $5 a$ \\
\hline 1d & $\mathrm{CH}_{2} \mathrm{Ph}$ & $\mathrm{Me}$ & $\mathrm{Me}$ & $\mathrm{Me}$ & $5 b$ \\
\hline $1 d$ & $\mathrm{CH}_{2} \mathrm{Ph}$ & $\mathrm{Me}$ & Et & $\mathrm{Et}$ & $5 c$ \\
\hline $1 e$ & $4-\mathrm{C}_{6} \mathrm{H}_{4} \mathrm{OMe}$ & $\mathrm{Me}$ & $\mathrm{Me}$ & $\mathrm{H}$ & $6 a$ \\
\hline $1 e$ & $4-\mathrm{C}_{6} \mathrm{H}_{4} \mathrm{OMe}$ & $\mathrm{Me}$ & $\mathrm{Ph}$ & $\mathrm{H}$ & $6 b$ \\
\hline $1 e$ & $4-\mathrm{C}_{6} \mathrm{H}_{4} \mathrm{OMe}$ & $\mathrm{Me}$ & $\mathrm{Me}$ & $\mathrm{Me}$ & $6 c$ \\
\hline 1f & 2-naphthyl & $\mathrm{Me}$ & $\mathrm{Me}$ & $\mathrm{Me}$ & 7 \\
\hline
\end{tabular}

The products 2-7 were purified by alumina chromatography and finally isolated as air-stable triflate salts in $69-95 \%$ yields. They were fully characterized by elemental analysis, IR and NMR spectroscopy (Figures S1-S32). The IR spectra (in $\mathrm{CH}_{2} \mathrm{Cl}_{2}$ solution) share a common pattern with three main bands; two of them are ascribable to the terminal and bridging carbonyl stretching vibrations and fall in the ranges $1986-1992 \mathrm{~cm}^{-1}$ and $1804-1814 \mathrm{~cm}^{-1}$, respectively. The third band is related to the iminium $\left(\mathrm{C}^{1}=\mathrm{N}\right)$ function and reveals a double bond character; however, its wavenumber is rather sensitive to the electronic properties of all vinyliminium substituents (i.e., R, Y, $\mathrm{R}^{\prime}$ and $\mathrm{R}^{\prime \prime}$ ). For instance, it occurs at 1644 and $1664 \mathrm{~cm}^{-1}$ in $\mathbf{2 a}$ and $\mathbf{5 a}$, respectively, the latter complex differing from the former for a $\mathrm{CH}_{3}$ group instead of $\mathrm{CH}_{2} \mathrm{Ph}$ on nitrogen. The substitution of the $\mathrm{C}^{2}$ carbon determines a significant decrease of the $\mathrm{C}^{1}=\mathrm{N}$ wavenumber, as well as a minor decrease for the CO signal [e.g., for 4a: $\tilde{v} / \mathrm{cm}^{-1}=1989(\mathrm{CO}), 1805(\mu-\mathrm{CO}), 1661\left(\mathrm{C}^{1}=\mathrm{N}\right)$; for 4c: $\tilde{v} / \mathrm{cm}^{-1}=1986(\mathrm{CO}), 1805(\mu-\mathrm{CO}), 1646\left(\mathrm{C}^{1}=\mathrm{N}\right)$ ]. The allyl moiety in 3a-c manifests itself with a weak infrared absorption at ca. $1640 \mathrm{~cm}^{-1}$ (double carbon-carbon bond). The NMR spectra of $\mathbf{2 a - c}$ (in acetone- $\mathrm{d}_{6}$ ) show a single set of resonances, and in particular the singlets due to the $\mathrm{Cp}$ rings, in the ${ }^{1} \mathrm{H}$ spectra, have been detected at ca. 5.6 and $5.3 \mathrm{ppm}$, pointing out their mutual cis arrangement. In fact, cis/trans isomerism was previously recognized in some analogous complexes, the trans form being associated to a diagnostic upfield shift of one $\mathrm{Cp}$ resonance $(\delta \leq 4.5 \mathrm{ppm})$ [65]. Consistently, the Cp signals of the remaining complexes 3-7 (apart from $5 \mathbf{c}$, vide infra) fall within the range $4.97-5.67 \mathrm{ppm}$, thus indicating cis configuration (acetone- $\mathrm{d}_{6}$ or $\mathrm{CDCl}_{3}$ solutions). However, two sets of signals are generally observed in the spectra of 3-7 with a ratio variable between 1.2 and 2 , related to $\mathrm{E}-\mathrm{Z}$ isomerism generated by the two possible orientations of the iminium substituents $(\mathrm{R} \neq \mathrm{Y})$. The $\mathrm{E}$ isomer is prevalent in $\mathbf{3 a}, \mathbf{4} \mathbf{b}, \mathbf{6} \mathbf{a}$ and $\mathbf{6} \mathbf{b}$, exhibiting highfield signals for the N-methyl [e.g., at $3.27\left({ }^{1} \mathrm{H}\right)$ and $41.8\left({ }^{13} \mathrm{C}\right) \mathrm{ppm}$ in the case of 3a]; the opposite $\mathrm{Z}$ isomer prevails in $\mathbf{3 b}, \mathbf{3 c}, \mathbf{4} \mathbf{c}, \mathbf{5 b}, \mathbf{5} \mathbf{c}, \mathbf{6 c}$ and $\mathbf{7}$ [e.g., for $\mathbf{3 b}$ : $\delta(\mathrm{NMe})=3.89\left({ }^{1} \mathrm{H}\right)$ and $\left.47.7\left({ }^{13} \mathrm{C}\right) \mathrm{ppm}\right]$. Analogous features were generally recognized on related vinyliminium complexes with $\mathrm{R}=\mathrm{CH}_{2} \mathrm{Ph}$ or $\mathrm{Xyl}$ and $\mathrm{Y}=\mathrm{Me}$ (see Introduction and Figure 1) $[39,66]$. In the case of $\mathbf{5 c}$, a comparison of the NMR data with the library of data available in the 
literature points out the existence in $\mathrm{CDCl}_{3}$ solution of trans- $\mathrm{Z}$ and cis-E isomers, in ca. 2:1 ratio; in detail, the $\mathrm{Cp}$ and $\mathrm{NMe}$ groups resonate at $4.85,4.35$ and $3.69 \mathrm{ppm}$ in the former isomer, and at 5.59, 5.40 and 2.90 in the latter $\left({ }^{1} \mathrm{H}\right.$ spectra).

Salient ${ }^{13} \mathrm{C}$ NMR features of 2-7 concern the carbon nuclei constituting the $\mathrm{C}_{3}$ bridging chain, which have been recognized at 223.6-230.4 ppm $\left(\mathrm{C}^{1}\right), 52.0-67.1 \mathrm{ppm}\left(\mathrm{C}^{2}\right)$ and 201.9-210.9 ppm $\left(C^{3}\right)$. The typical low-field values for $C^{1}$ and $C^{3}$ reflect the (amino)alkylidene and bridging alkylidene nature of these centers, respectively [31]; on the other hand, the interval found for $\mathrm{C}^{2}$ indicates a partial alkenic nature, and the presence of an alkyl substituent causes a downfield shift by 10-15 ppm (e.g., $\delta=52.9 \mathrm{ppm}$ for $\mathbf{2 a}$ and $65.7 \mathrm{ppm}$ for $\mathbf{2 c}$ ).

The structures of $\mathbf{2} \mathbf{c}$ and $\mathbf{3 a}$ were confirmed by single-crystal X-ray diffraction studies: a view of the cation of 3a is shown in Figure 2, with relevant bonding parameters in the caption, while a view of the cation of $2 \mathrm{c}$ is supplied as Supplementary Materials (Figure S33). In both structures, the $\mathrm{Cp}$ ligands are cis oriented, while the N-substituents in $3 a$ are arranged according to the $\mathrm{E}$ configuration. In $\mathbf{3} \mathbf{a}$, the bridging $\mathrm{C}^{3}$ carbon is slightly asymmetric between the two irons [Fe(2)-C(3) 2.036(4) and $\mathrm{Fe}(1)-\mathrm{C}(3) 1.940(4) \AA]$, while the bridging carbonyl exhibits a lower asymmetry [Fe(2)-C(12) 1.934(4) and Fe(1)-C(12) 1.911(4) $\AA$ ]. The N(1)-C(1) [1.285(4) $\AA], C(1)-C(2)[1.419(5) \AA]$ and C(2)-C(3) [1.409(5) $\AA]$ distances evidence an extensive charge delocalization, as already found in similar complexes $[39,44,66]$, suggesting that the representation of the bridging ligand as vinyliminium is appropriate but not univocal. In particular, a comparison between the $C(2)-C(3)$ distance and $C(6)-C(7)[1.487(5) \AA]$ and $\mathrm{C}(7)-\mathrm{C}(8)[1.319(5) \AA]$ outlines that the former is intermediate between a single and a double $\mathrm{Csp} \mathrm{p}^{2}-\mathrm{Csp} p^{2}$ bond.

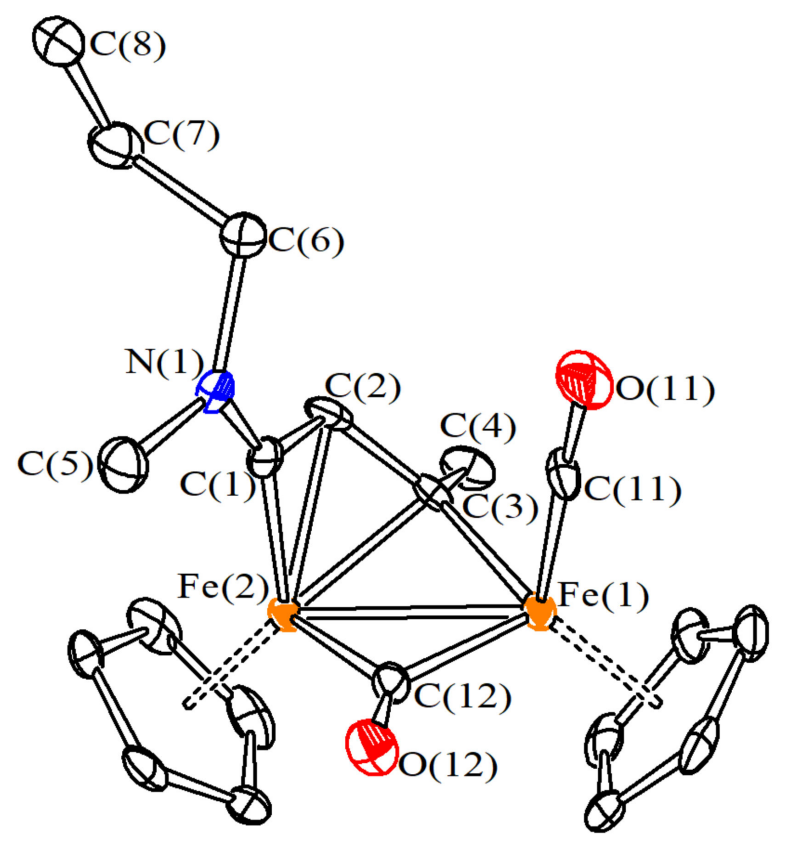

Figure 2. View of the cation of 3a. H atoms have been omitted for clarity. Displacement ellipsoids are at the $50 \%$ probability level. Selected bond lengths $(\AA)$ and angles $\left(^{\circ}\right)$ : $\mathrm{Fe}(1)-\mathrm{Fe}(2) 2.5426(7)$, $\mathrm{Fe}(1)-\mathrm{C}(11)$ 1.763(3), $\mathrm{Fe}(1)-\mathrm{C}(12)$ 1.911(4), $\mathrm{Fe}(2)-\mathrm{C}(12)$ 1.934(4), $\mathrm{Fe}(2)-\mathrm{C}(1)$ 1.851(3), $\mathrm{Fe}(2)-\mathrm{C}(2)$ 2.055(3), $\mathrm{Fe}(2)-\mathrm{C}(3)$ 2.036(4), $\mathrm{Fe}(1)-\mathrm{C}(3)$ 1.940(4), C(1)-N(1) 1.285(4), C(1)-C(2) 1.419(5), C(2)-C(3) 1.409(5), $\mathrm{N}(1)-\mathrm{C}(5)$ 1.466(5), N(1)-C(6) 1.481(4), C(6)-C(7) 1.487(5), C(7)-C(8) 1.319(5), C(11)-O(11) 1.144(4), $\mathrm{C}(12)-\mathrm{O}(12)$ 1.172(4), $\mathrm{Fe}(1)-\mathrm{C}(11)-\mathrm{O}(11)$ 178.2(4), $\mathrm{Fe}(1)-\mathrm{C}(12)-\mathrm{Fe}(2)$ 82.79(15), Fe(1)-C(3)-Fe(2) 79.47(14), $\mathrm{Fe}(1)-\mathrm{C}(3)-\mathrm{C}(2)$ 120.7(3), C(3)-C(2)-C(1) 116.2(3), C(2)-C(1)-Fe(2) 76.6(2), C(1)-N(1)-C(5) 121.7(3), C(1)$\mathrm{N}(1)-\mathrm{C}(6)$ 121.3(3), C(5)-N(1)-C(6) 117.0(3), N(1)-C(6)-C(7) 112.7(3), C(6)-C(7)-C(8) 122.5(4).

\subsection{Solubility and Stability in Water and Determination of Octanol-Water Partition Coefficients}

The water solubility of complexes was measured by means of ${ }^{1} \mathrm{H}$ NMR spectroscopy (Table 3). In $\mathrm{D}_{2} \mathrm{O}$, most of the complexes showed an appreciable solubility, falling in the 
millimolar range, and an isomer ratio slightly different with respect to what is found in acetone- $\mathrm{d}_{6}$ or $\mathrm{CDCl}_{3}$. The solubilities of $\mathbf{3 a} \mathbf{a}-\mathbf{c}, \mathbf{4 a}-\mathbf{c}$ and $\mathbf{6 a}$ (ranging from 1.02 to $4.02 \mathrm{~g} \cdot \mathrm{L}^{-1}$ ) are comparable to that of cisplatin (ca. $3 \mathrm{~g} \cdot \mathrm{L}^{-1}$ ) and other common platinum drugs [67-70]. On the other hand, $\mathbf{2 b , c}$, containing more than one phenyl group, and $\mathbf{7}$, containing a naphthyl, are almost insoluble in $\mathrm{D}_{2} \mathrm{O}$.

Table 3. Solubility of diiron complexes in $\mathrm{D}_{2} \mathrm{O}$ at $21{ }^{\circ} \mathrm{C}\left({ }^{1} \mathrm{H} \mathrm{NMR}, \mathrm{Me}_{2} \mathrm{SO}_{2}\right.$ internal standard), residual \% in DMSO-d $\mathrm{d}_{6} / \mathrm{D}_{2} \mathrm{O}(2: 1 \mathrm{v} / v)$ after $72 \mathrm{~h}$ at $37^{\circ} \mathrm{C}\left({ }^{1} \mathrm{H} \mathrm{NMR}, \mathrm{Me}_{2} \mathrm{SO}_{2}\right.$ internal standard $)$ and octanol-water partition coefficients at $21{ }^{\circ} \mathrm{C}\left(\log P_{\text {ow }}, \mathrm{UV}-\right.$ Vis $)$. a Stability evaluated in neat $\mathrm{D}_{2} \mathrm{O}$.

\begin{tabular}{ccccc}
\hline Compound & Solubility/mol· $\mathbf{L}^{-\mathbf{1}}$ Solubility/g $\cdot \mathbf{L}^{-\mathbf{1}}$ & Stability $\%$ & Log $\boldsymbol{P}_{\mathbf{o w}}$ \\
\hline $\mathbf{2 a}$ & $4.33 \times 10^{-4}$ & 0.30 & 81 & $0.45 \pm 0.04$ \\
\hline $\mathbf{2 b}$ & $<1 \times 10^{-4}$ & $<0.08$ & $=$ & $1.4 \pm 0.2$ \\
\hline $\mathbf{2 c}$ & $<1 \times 10^{-4}$ & $<0.07$ & 87 & $0.56 \pm 0.08$ \\
\hline $\mathbf{3 a}$ & $6.43 \times 10^{-3}$ & 3.66 & $93^{\mathrm{a}}$ & $-0.75 \pm 0.01$ \\
\hline $\mathbf{3 b}$ & $2.34 \times 10^{-3}$ & 1.48 & 68 & $-0.09 \pm 0.01$ \\
\hline $\mathbf{3 c}$ & $6.89 \times 10^{-3}$ & 4.02 & $85^{\mathrm{a}}$ & $-0.77 \pm 0.01$ \\
\hline $\mathbf{4 a}$ & $3.49 \times 10^{-3}$ & 2.13 & 95 & $-0.29 \pm 0.03$ \\
\hline $\mathbf{4 b}$ & $1.52 \times 10^{-3}$ & 1.02 & 65 & $0.41 \pm 0.02$ \\
\hline $\mathbf{4 c}$ & $2.63 \times 10^{-3}$ & 1.64 & 95 & $-0.17 \pm 0.01$ \\
\hline $\mathbf{5 a}$ & $5.41 \times 10^{-4}$ & 0.34 & 85 & $-0.26 \pm 0.01$ \\
\hline $\mathbf{5 b}$ & $1.52 \times 10^{-3}$ & 0.96 & 90 & $-0.43 \pm 0.01$ \\
\hline $\mathbf{5 c}$ & $1.10 \times 10^{-3}$ & 0.73 & 84 & $0.13 \pm 0.01$ \\
\hline $\mathbf{6 a}$ & $2.22 \times 10^{-3}$ & 1.41 & 94 & $-0.46 \pm 0.01$ \\
\hline $\mathbf{6 b}$ & $4.98 \times 10^{-4}$ & 0.35 & 76 & $0.37 \pm 0.04$ \\
\hline $\mathbf{6 c}$ & $1.06 \times 10^{-3}$ & 0.69 & 66 & $-0.21 \pm 0.01$ \\
\hline $\mathbf{7}$ & $<1 \times 10^{-4}$ & $<0.07$ & 66 & $0.38 \pm 0.02$ \\
\hline
\end{tabular}

Next, the stability of the complexes was assessed by ${ }^{1} \mathrm{H}$ NMR spectroscopy in DMSO$\mathrm{d}_{6} / \mathrm{D}_{2} \mathrm{O}$ solutions, stored at $37^{\circ} \mathrm{C}$ for $72 \mathrm{~h}$ (Table 3). In general, the complexes exhibited a considerable stability, with an average of $83 \%$ of starting material detected at the end of the experiment. Especially those complexes with $\mathrm{R}^{\prime}=\mathrm{Me}$ and $\mathrm{R}^{\prime \prime}=\mathrm{H}$ appear robust (mean percentage $=90 \%$ ). The slow decomposition of the complexes is featured by the formation of a minor amount of precipitate suggesting extensive rupture of the diiron scaffold [71], while new organometallic species were not detected in solution. The octanolwater partition coefficients were measured by means of a UV-Vis technique (Table 3, see Experimental for details). Most complexes display a substantial amphiphilic character, with $\log P_{\text {ow }}$ values ranging from -0.77 to 1.30 . In general, the presence of the phenyl group on the $\mathrm{C}^{3}$ carbon leads to a significant increase in lipophilicity, while the allyl group on the iminium moiety determines the opposite effect. Complex $\mathbf{2} \mathbf{b}$, containing three phenyl units, displays the highest $\log P_{\text {ow }}$ value (1.4) and was excluded from the biological tests due to insufficient solubility.

\subsection{Cytotoxicity}

Firstly, the antiproliferative activity of the diiron complexes was assessed on human ovarian carcinoma A2780 cancer cells and, to estimate the selectivity, also on nontumoral Balb/3T3 clone A31 cells (Table 4 and Figure S34). Cisplatin was employed as a reference. In general, diiron complexes exhibit strong cytotoxicity against the considered cancer cell line, with $\mathrm{IC}_{50}$ values falling in the low micromolar range. Furthermore, an impressive 
selectivity was recognized with respect to the Balb/3T3 cell line: the selectivity index (S.I.) ranges from 7 to 52 , while the value for cisplatin is only 2 (Table 4 ).

Table 4. $\mathrm{IC}_{50}$ values $(\mu \mathrm{M})$ determined for diiron complexes and cisplatin on human ovarian carcinoma (A2780), human ovarian carcinoma cisplatin-resistant (A2780cisR) and murine embryonic fibroblast (Balb/3T3 clone A31) cell lines after $72 \mathrm{~h}$ exposure. Values are given as mean \pm standard deviation. Selectivity index (S.I.) calculated as the ratio between $\mathrm{IC}_{50}$ for Balb/3T3 and $\mathrm{IC}_{50}$ for $\mathrm{A} 2780$.

\begin{tabular}{ccccc}
\hline Compound & A2780 & A2780cisR & Balb/3T3 & S.I. \\
\hline $\mathbf{2 a}$ & $2.0 \pm 0.7$ & $=$ & $14 \pm 4$ & 7 \\
$\mathbf{2 c}$ & $1.91 \pm 0.15$ & $=$ & $18 \pm 3$ & 9 \\
$\mathbf{3 a}$ & $17.7 \pm 0.8$ & $=$ & $>100$ & $>5.6$ \\
$\mathbf{3 b}$ & $6.0 \pm 0.8$ & $29 \pm 3$ & $>100$ & $>16$ \\
$\mathbf{3} \mathbf{c}$ & $17 \pm 3$ & $=$ & $>100$ & $>5.9$ \\
$\mathbf{4 a}$ & $3.3 \pm 0.4$ & $11.6 \pm 1.3$ & $>100$ & $>30$ \\
$\mathbf{4 b}$ & $2.6 \pm 0.3$ & $=$ & $35 \pm 3$ & 13 \\
$\mathbf{4} \mathbf{c}$ & $1.8 \pm 0.2$ & $11.4 \pm 0.9$ & $94 \pm 16$ & 52 \\
$\mathbf{5 a}$ & $7.1 \pm 0.4$ & $=$ & $>100$ & $>14$ \\
$\mathbf{5 b}$ & $5.1 \pm 0.3$ & $12 \pm 4$ & $>100$ & $>19$ \\
$\mathbf{5 c}$ & $3.75 \pm 0.14$ & $=$ & $90 \pm 8$ & 24 \\
$\mathbf{6 a}$ & $3.5 \pm 0.5$ & $=$ & $94 \pm 4$ & 27 \\
$\mathbf{6 b}$ & $3.8 \pm 0.4$ & $=$ & $39 \pm 3$ & 10 \\
$\mathbf{6 c}$ & $3.8 \pm 0.4$ & $17 \pm 3$ & $>100$ & $>26$ \\
$\mathbf{7}$ & $2.2 \pm 0.2$ & $=$ & $48 \pm 3$ & 22 \\
cisplatin & $0.40 \pm 0.07$ & $26 \pm 3$ & $0.8 \pm 0.2$ & 2 \\
\hline
\end{tabular}

The cytotoxicity of the complexes against the A2780 cancer cell line approximately correlates with the lipophilicity, and actually the most hydrophilic compounds $\mathbf{3 a}$ and $3 c\left(\log P_{\text {ow }}<-0.7\right)$, bearing $\mathrm{R}=\mathrm{CH}_{2} \mathrm{CH}=\mathrm{CH}_{2}$, display a relatively lower potency $\left(\mathrm{IC}_{50} \approx 17 \mu \mathrm{M}\right)$. On the other hand, $\mathbf{4 a}, \mathbf{4} \mathbf{c}, \mathbf{5 a}, \mathbf{5 b}, \mathbf{6} \mathbf{a}$ and $\mathbf{6} \mathbf{c}$, bearing $\mathrm{R}=$ cyclohexyl, benzyl or 4-methoxyphenyl, show a potent activity despite the negative $\log P_{\text {ow }}$ values.

The analogous complexes $\mathbf{5 b}$ and $\mathbf{5} \mathbf{c}$, differing to each other for the alkyl chain on $\mathrm{C}^{2}$ and $\mathrm{C}^{3}$, display comparable activity. The activity of $3 \mathbf{a}\left(\mathrm{IC}_{50}=17.7 \pm 0.8 \mu \mathrm{M}\right.$, $\left.\log P_{\text {ow }}=-0.75\right)$ is enhanced compared to that previously determined on the same cell line for the analogous complex $\left[\mathrm{Fe}_{2} \mathrm{Cp}_{2}(\mathrm{CO})(\mu-\mathrm{CO})\left\{\mu-\eta^{1}: \eta^{3}-\mathrm{C}^{3}(\mathrm{Me}) \mathrm{C}^{2} \mathrm{HC}^{1} \mathrm{NMe}_{2}\right\}\right] \mathrm{CF}_{3} \mathrm{SO}_{3}$ $\left(\mathrm{IC}_{50}=35 \pm 3 \mu \mathrm{M}, \log P_{\mathrm{ow}}=-0.3\right)$ [39], indicating that the replacement of one methyl $\mathrm{N}$-substituent with the allyl may improve the anticancer activity. Conversely, $\mathrm{IC}_{50}$ values of $0.50 \pm 0.06 \mu \mathrm{M}$ and $0.90 \pm 0.06 \mu \mathrm{M}$ were previously found for, respectively, $\left[\mathrm{Fe}_{2} \mathrm{Cp}_{2}(\mathrm{CO})(\mu-\mathrm{CO})\left\{\mu-\eta^{1}: \eta^{3}-\mathrm{C}^{3}(\mathrm{Me}) \mathrm{C}^{2}(\mathrm{Me}) \mathrm{C}^{1} \mathrm{NMe}(\mathrm{Xyl})\right\}\right] \mathrm{CF}_{3} \mathrm{SO}_{3}\left(\log P_{\mathrm{ow}}=0.0\right)$ and $\left[\mathrm{Fe}_{2} \mathrm{Cp}_{2}(\mathrm{CO})(\mu-\mathrm{CO})\left\{\mu-\eta^{1}: \eta^{3}-\mathrm{C}^{3}(\mathrm{Ph}) \mathrm{C}^{2} \mathrm{HC}^{1} \mathrm{NMe}(\mathrm{Xyl})\right\}\right] \mathrm{CF}_{3} \mathrm{SO}_{3}\left(\log P_{\mathrm{ow}}=0.4\right)$ [39], thus outlining the beneficial effect provided by a xylyl ring among possible aryl groups (see data related to 7 and $\mathbf{6 b}$ ).

Note that here $\mathrm{R}$ = cyclohexyl, benzyl and 4-methoxyphenyl supply the highest selectivity indexes, and especially the combination with $\mathrm{R}^{\prime}=\mathrm{R}^{\prime \prime}=\mathrm{Me}$ or Et is convenient (average S.I. $\geq 30$ ). It is worth mentioning that $\mathrm{R}=$ cyclohexyl and $\mathrm{R}=4$-methoxyphenyl contribute to the best cytotoxicity profiles also concerning the series of aminocarbyne complexes 1a-f [37]. Complex 4c, derived from the assembly of cyclohexylisocyanide and 2-butyne (Table 2), appears as the most performant within the series of vinyliminium complexes 2-7. The favorable effect on the anticancer activity provided by the decoration of metal complexes with the cyclohexyl (Cy) moiety has been documented in the literature, attributed to the compact and hydrophobic structure of Cy facilitating the entrance of the drug into the tumor cell [72-74].

A selection of the most promising compounds was further investigated. First, the cytotoxicity of $\mathbf{3 b}, \mathbf{4 a}, \mathbf{4 c}, \mathbf{5 b}$ and $\mathbf{6 c}$ was measured on the cisplatin-resistant A2780cisR cell line. Overall, a loss of activity was observed with respect to the cisplatin-sensitive cell line 
(A2780), nevertheless $4 a, 4 c$ and $5 b$ maintain a higher level of activity than that of cisplatin under the same conditions.

\subsection{ROS Production}

Previous findings pointed out that diiron vinyliminium complexes exert their anticancer activity mainly by unbalancing cell redox homeostasis, and this phenomenon may be ascribable to several routes possibly taking place inside the cells: (1) complex reduction by neutralization of the net cationic charge; (2) fragmentation into monoiron derivatives; and (3) disassembly of the diiron core releasing the two $\mathrm{Fe}^{+\mathrm{I}}$ centers $[36,39,40,45]$. According to this premise, we considered of interest to evaluate the ability of selected complexes, $3 b, 4 a, 4 c, 5 b$ and $\mathbf{6 c}$, to induce intracellular ROS production. Thus, fluorescence measurements were carried out with the DCFH-DA assay, by exposing A2780 cells to, respectively, the diiron complexes, the reference drug cisplatin and $\mathrm{H}_{2} \mathrm{O}_{2}$ (positive control). All the diiron complexes elicited an appreciable ROS production, significantly higher than that of cisplatin, especially after ca. $20 \mathrm{~h}$ and progressively increasing up to $24 \mathrm{~h}$ (Figure 3 ). The benzyl complex $5 \mathrm{~b}$ revealed the most effective of the series in inducing the ROS production, and this outcome may be associated with the high cytotoxicity exhibited by this complex against the cancer cells, despite its relatively low hydrophobicity.
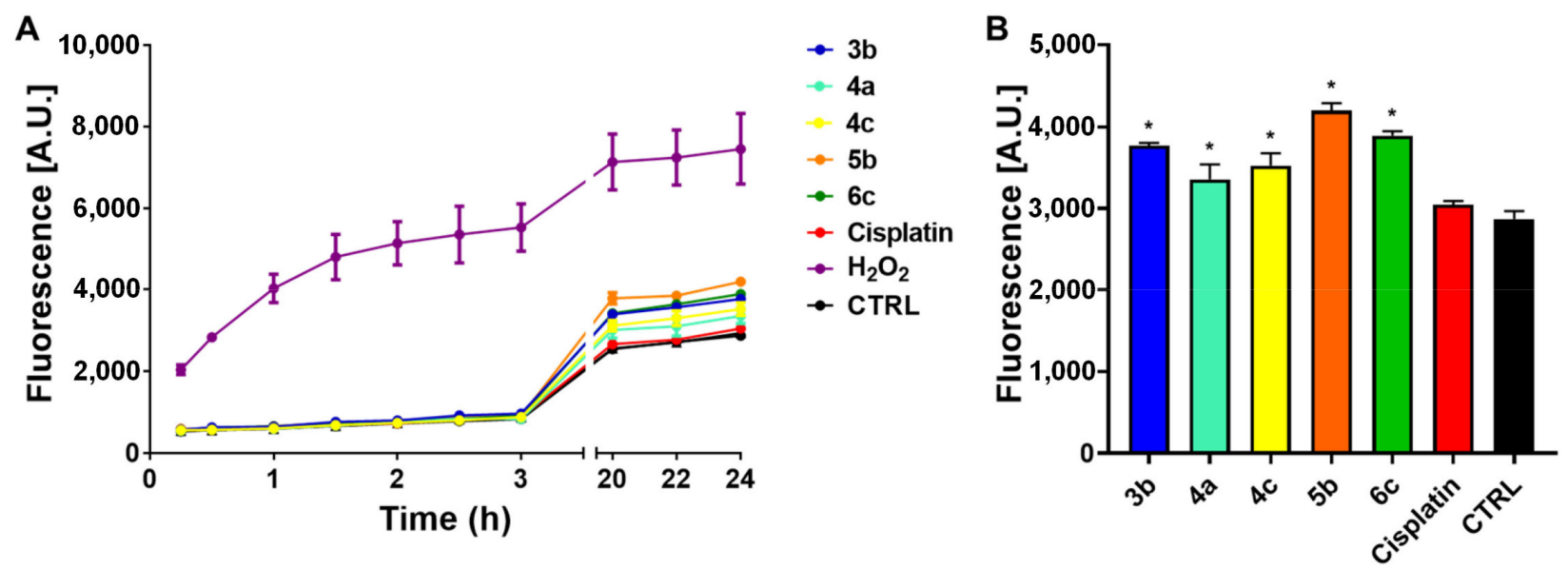

Figure 3. Fluorescence kinetic measurements of intracellular reactive oxygen species (ROS). A2780 cells incubated (A) up to $24 \mathrm{~h}$ and (B) for $24 \mathrm{~h}$ with $20 \mu \mathrm{M}$ of diiron complexes at $37^{\circ} \mathrm{C}$ and $5 \% \mathrm{CO}_{2}$. Results are expressed as the mean of three analyses with standard deviation. Values marked with * are significantly different from the control $\left({ }^{*} p<0.05\right)$.

\subsection{Protein Binding Studies}

Recent results on the anticancer activity of the aminocarbyne complex 1e highlighted a possible mechanism involving the inhibition of the selenoenzyme thioredoxin reductase (TrxR) [36]; more specifically, substantial inhibition of this enzyme was detected in human pancreatic PSN-1 cancer cells. Former studies by other authors demonstrated a similar mode of action by ferrocenyl drug candidates [75]. Therefore, we became interested in elucidating the potentiality of the new vinyliminium complexes to inhibit TrxR.

During the past years, high-resolution electrospray ionization mass spectrometry (HRESI-MS) has emerged as a valuable and powerful tool to study the formation of adducts derived from the interaction of metallodrugs with biomolecules [76-78]. Moreover, this technique allows the identification of the precise nature of the fragments attached to protein side chains and, thus, to infer some relevant mechanistic information [79-81].

Since the amount of native TrxR required for the ESI-MS experiment, albeit low, can hardly be found commercially available at a reasonable cost, for the present study we opted for a model system that has been already successfully employed [82]. The model is a synthetic dodecapeptide (TrxR-pept) mimicking the C-terminal tryptic portion of the TrxR enzyme, 
consisting in the amino acidic sequence Ac-SGGDILQSG[CU]G-NH ${ }_{2}$ \} and featured by the presence of the peculiar $\{$-Cys-Sec- $\}$ motif (Cys = cysteine; $\mathrm{Sec}=$ selenocysteine).

First, we verified the suitability of the model system by analyzing its interaction with complex 1e, for which TrxR inhibition was previously recognized by enzymatic assay (vide infra). The resulting ESI mass spectrum is shown in Figure 4. It contains three main peaks at $m / z$ 1183.3859, due to unreacted TrxR-pept, and at $m / z 1205.3771$ and 1221.3413, corresponding to the adducts of TrxR-pept with sodium and potassium, respectively. In addition, three more peaks of lower intensity are ascribable to the metalated dodecapeptide. Notably, the signal at $\mathrm{m} / \mathrm{z} 1237.3218$ is in good accordance with the presence of a $[\text { TrxR-pept }+\mathrm{Fe}-\mathrm{H}]^{+}$species. Moreover, the signals at $\mathrm{m} / \mathrm{z} 1253.3236$ and 1259.2970 were assigned to the iron-bound TrxR-pept with the additional presence of one oxygen atom and one sodium ion, respectively. Intriguingly, the degradation of diiron bis-cyclopentadienyl carbonyl complexes inside the tumor cell, releasing the iron atoms, has been hypothesized to represent a major mechanism for the antiproliferative activity $[36,37,39,45]$.

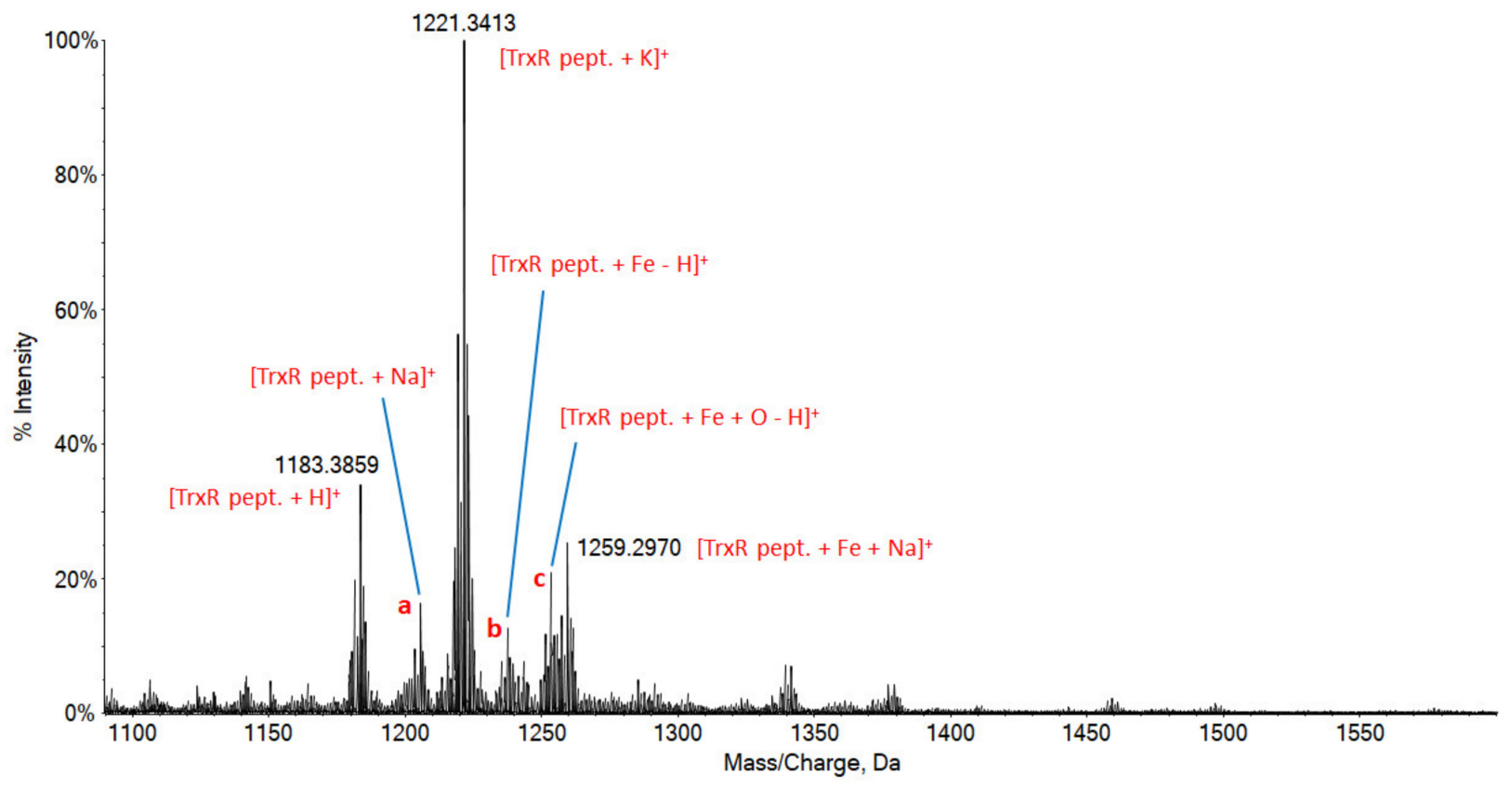

Figure 4. High-resolution ESI mass spectrum of 1 e incubated for $24 \mathrm{~h}$ at $37^{\circ} \mathrm{C}$ with $10^{-5} \mathrm{M}$ TrxR-pept solution in water; $1: 1$ peptide to complex ratio. $0.1 \% v / v$ of formic acid was added just before infusion. Unlabeled peaks: $\mathbf{a}, m / z 1205.3771 ; \mathbf{b}, m / z$ 1237.3218; c, $m / z$ 1253.3236.

At this stage of the study, we were not able to ascertain the oxidation state of the iron center nor its coordinative surrounding; however, it is reasonable to assume that the binding of iron is made possible by the coordination of sulfur and selenium atoms belonging to the $\{-\mathrm{Cys}-\mathrm{Sec}-\}$ unit. This hypothesis is in alignment with the significant TrxR inhibitory activity manifested by $1 \mathbf{e}$ [37], which suggests a direct involvement of the TrxR catalytic site.

Following the coherent results obtained for $1 \mathbf{e}$, we extended the same method to test the TrxR inhibition ability of selected vinyliminium complexes. Thus, $\mathbf{2 c}, \mathbf{3 b}, \mathbf{4 a}, \mathbf{4 c}, \mathbf{5 b}, \mathbf{6 b}$, $\mathbf{6 c}$ and $\mathbf{7}$ were incubated at $37^{\circ} \mathrm{C}$ for $24 \mathrm{~h}$ with TrxR-pept in 1:1 complex-to-peptide ratio.

The recorded ESI mass spectra share a common pattern resembling that obtained for 1e (see Figure S35 for a representative spectrum). More in detail, in addition to the signals of unreacted TrxR-pept and its adducts with sodium and potassium, one relevant signal at $\mathrm{m} / \mathrm{z} 1237.3172$ was recognized, attributed to [TrxR-pept $+\mathrm{Fe}-\mathrm{H}]^{+}$. This outcome suggests that diiron vinyliminium complexes may actually act as inhibitors of the thioredoxin reductase enzyme, analogously to diiron aminocarbyne complexes such as 1e. 
Then, we analyzed the interaction of the vinyliminium complexes $\mathbf{2 c}, \mathbf{3 b} \mathbf{b} \mathbf{4} \mathbf{a}, \mathbf{4} \mathbf{c}$, $5 b, 6 b, 6 c$ and 7 with a small model protein, i.e., cytochrome c (Cyt c). The resulting ESI mass spectra indicated the substantial chemical inertness of the cationic part of the complexes towards Cyt c. In fact, the spectra only show the signal due to the unreacted protein (12358.451 Da) and two other peaks at 12508.414 and $12659.366 \mathrm{Da}$, corresponding to the adducts of Cyt $\mathrm{c}$ with one and two $\mathrm{CF}_{3} \mathrm{SO}_{3}{ }^{-}$anions, respectively (Figure S36). This absence of reactivity confirms the strong robustness of 2-7, and represents a partial indication that the anticancer activity of these complexes is selectively directed to the TrxR inhibition, the possible side-reactions with other cellular or plasma proteins being unlikely. Accordingly, previous fluorescence experiments on the interaction of analogous diiron complexes with bovine serum albumin (BSA) pointed out the occurrence of a reversible binding event $[39,46]$, potentially adequate to BSA-mediated transport and diffusion of the drug $[83,84]$. Note that the establishment of unselective, strong covalent interactions between a metal drug and proteins is, in principle, one of the routes for off-target reactions causing undesired side effects.

\section{Conclusions}

Diiron complexes based on the $\left\{\mathrm{Fe}_{2} \mathrm{Cp}_{2}(\mathrm{CO})_{2}\right\}$ scaffold and containing a bridging vinyliminium ligand display some notable properties for a potential drug, i.e., the presence of a biocompatible metal element, straightforward synthesis from inexpensive precursors, appreciable water solubility and/or amphiphilicity, and remarkable stability in aqueous media. The wide structural variability is guaranteed by the cooperativity provided by the bimetallic system. Following preliminary studies on other similar compounds, here we have synthesized a series of new diiron vinyliminium complexes, which have been investigated for their in vitro anticancer activity. In particular, a variety of alkyl and aryl groups $(R, Y)$ on the iminium function has been screened for the first time. Overall, the results point out a significant and fine influence of all vinyliminium substituents $\left(R, Y, R^{\prime}\right.$ and $\mathrm{R}^{\prime \prime}$ ) on the physico-chemical properties of the complexes and their cytotoxicity, and especially the choice of $\mathrm{R}$ and $\mathrm{Y}$ is crucial to provide an optimal profile, with both electronic and steric factors presumably playing a role. Complex $4 c$, bearing a cyclohexyl moiety on the nitrogen, emerges for its high antiproliferative activity (associated with a slightly negative Log $P_{o w}$ value) towards A2780 and A2780cisR cancer cells and impressive selectivity compared to Balb/3T3 healthy cells (selectivity indexes are 52 and 8, respectively). In accordance with previous findings, targeted studies reveal the probable interference of the complexes with the cellular redox balance, triggering the production of reactive oxygen species. Moreover, mass spectrometry experiments suggest that, although the complexes seem sufficiently robust to resist degradation by common proteins, the peculiar structure of the catalytic site of TrxR might accelerate the intracellular disassembly of the diiron scaffold, resulting in the enzyme inhibition via incorporation of iron. Advanced studies are in course to develop diiron vinyliminium complexes as a suitable class of organometallic anticancer candidates.

Supplementary Materials: The following are available online at https: / www.mdpi.com/article / 10.3390/pharmaceutics13081158/s1: Figures S1-S32: NMR spectra of complexes; Figure S33: X-ray structure of 2c; Figure S34: Dose-response cell viability curves; Figures S35-S36: Representative high-resolution ESI mass spectra for the interaction of $\mathbf{3 b}$ with the TrxR dodecapeptide (TrxR-pept) and Cyt c. CCDC reference numbers 2087828 (2c) and 2087829 (3a) contain the supplementary crystallographic data for the X-ray studies reported in this paper. These data can be obtained free of charge at www.ccdc.cam.ac.uk/conts/retrieving.html (or from the Cambridge Crystallographic Data Centre, 12, Union Road, Cambridge CB2 1EZ, UK; e-mail: deposit@ccdc.cam.ac.uk).

Author Contributions: Conceptualization, F.M. and F.C.; methodology, S.B., L.B., G.R., A.P. and S.Z.; investigation, S.B., L.B., G.R., A.P. and S.Z.; data curation, S.B., L.B., G.R., A.P., S.Z., F.C. and F.M.; writing-original draft preparation, F.M.; writing-review and editing, S.B., L.B., A.P., S.Z., G.P. and F.M.; supervision, F.C. and F.M.; funding acquisition, L.B., A.P., G.P., F.C. and F.M. All authors have read and agreed to the published version of the manuscript. 
Funding: This research was funded by the University of Pisa (PRA_2020_39).

Institutional Review Board Statement: Not applicable.

Informed Consent Statement: Not applicable.

Data Availability Statement: Data are contained within the article or Supplementary Materials.

Acknowledgments: A.P. thanks Luigi Messori (Dept. of Chemistry “U. Schiff,” University of Florence) for making available the TripleTOF ${ }^{\circledR} 5600^{+}$mass spectrometer.

Conflicts of Interest: The authors declare no conflict of interest.

\section{References and Notes}

1. Gibson, D. Platinum(IV) anticancer agents; are we en route to the holy grail or to a dead end? J. Inorg. Biochem. 2021, 217, 111353. [CrossRef]

2. Johnstone, T.C.; Suntharalingam, K.; Lippard, S.J. The Next Generation of Platinum Drugs: Targeted Pt(II) Agents, Nanoparticle Delivery, and Pt(IV) Prodrugs. Chem. Rev. 2016, 116, 3436-3486. [CrossRef]

3. Murray, B.S.; Dyson, P.J. Recent progress in the development of organometallics for the treatment of cancer. Curr. Opin. Chem. Biol. 2020, 56, 28-34. [CrossRef] [PubMed]

4. Chellan, P.; Sadler, P.J. Enhancing the Activity of Drugs by Conjugation to Organometallic Fragments. Chem. Eur. J. 2020, 26, 8676-8688. [CrossRef] [PubMed]

5. Štarha, P.; Trávníček, Z. Non-platinum complexes containing releasable biologically active ligands. Coord. Chem. Rev. 2019, 395, 130-145. [CrossRef]

6. Bratsos, I.; Gianferrara, T.; Alessio, E.; Hartinger, C.G.; Jakupec, M.A.; Keppler, B.K. Ruthenium and Other Non-Platinum Anticancer Compounds. In Bioinorganic Medicinal Chemistry; Alessio, E., Ed.; Wiley-VCH: Weinheim, Germany, 2011 ; pp. 151-174.

7. Boros, E.; Dyson, P.J.; Gasser, G. Classification of Metal-Based Drugs according to Their Mechanisms of Action. Chem 2020, 6, 41-60. [CrossRef]

8. Anthony, E.J.; Bolitho, E.M.; Bridgewater, H.E.; Carter, O.W.L.; Donnelly, J.M.; Imberti, C.; Lant, E.C.; Lermyte, F.; Needham, R.J.; Palau, M.; et al. Metallodrugs are unique: Opportunities and challenges of discovery and development. Chem. Sci. 2020, 11, 12888-12917. [CrossRef]

9. Haas, K.L.; Franz, K.J. Application of Metal Coordination Chemistry To Explore and Manipulate Cell Biology. Chem. Rev. 2009, 109, 4921-4960. [CrossRef]

10. Riddell, I.A.; Lippard, S.J. Cisplatin and Oxaliplatin: Our Current Understanding of Their Actions. Met. Ions Life Sci. $2018,18,1-42$.

11. Yu, C.; Wang, Z.; Sun, Z.; Zhang, L.; Zhang, W.; Xu, Y.; Zhang, J.-J. Platinum-Based Combination Therapy: Molecular Rationale, Current Clinical Uses, and Future Perspectives. J. Med. Chem. 2020, 63, 13397-13412. [CrossRef] [PubMed]

12. Green, A.J.; Planchart, A. The neurological toxicity of heavy metals: A fish perspective. CBPC 2018, 208, 12-19. [CrossRef] [PubMed]

13. Campbell, J.M.; Bateman, E.; Peters, M.D.J.; Bowen, J.M.; Keefe, D.M.; Stephenson, M.D. Fluoropyrimidine and platinum toxicity pharmacogenetics: An umbrella review of systematic reviews and meta-analyses. Pharmacogenomics 2016, 17, 435-451. [CrossRef] [PubMed]

14. Oun, R.; Moussa, Y.E.; Wheate, N.J. The side effects of platinum-based chemotherapy drugs: A review for chemists. Dalton Trans. 2018, 47, 6645-6653. [CrossRef] [PubMed]

15. Siddik, Z.H. Cisplatin: Mode of cytotoxic action and molecular basis of resistance. Oncogene 2003, 22, 7265-7279. [CrossRef]

16. Goldstein, R.S.; Mayor, G.H. Minireview. The nephrotoxicity of cisplatin. Life Sci. 1983, 32, 685-690. [CrossRef]

17. Sanchez, M.; Sabio, L.; Galvez, N.; Capdevila, M.; Dominguez-Vera, J.M. Iron chemistry at the service of life. IUBMB Life 2017, 69, 382-388. [CrossRef]

18. Crichton, R. Iron Metabolism-From Molecular Mechanisms to Clinical Consequences, 4th ed.Wiley: Hoboken, NJ, USA, 2016.

19. Wani, W.A.; Baig, U.; Shreaz, S.; Shiekh, R.A.; Iqbal, P.F.; Jameel, E.; Ahmad, A.; Mohd-Setapar, S.H.; Mushtaque, M.; Hun, L.T. Recent advances in iron complexes as potential anticancer agents. New J. Chem. 2016, 40, 1063-1090. [CrossRef]

20. Basu, U.; Roy, M.; Chakravarty, A.R. Recent advances in the chemistry of iron-based chemotherapeutic agents. Coord. Chem. Rev. 2020, 417, 213339. [CrossRef]

21. Simenel, A.A.; Morozova, E.A.; Snegur, L.V.; Zykova, S.I.; Kachala, V.V.; Ostrovskaya, L.A.; Bluchterova, N.V.; Fomina, M.M. Simple route to ferrocenylalkyl nucleobases. Antitumor activity in vivo. Appl. Organomet. Chem. 2009, 23, 219-224. [CrossRef]

22. Simenel, A.A.; Samarina, S.V.; Snegur, L.V.; Starikova, Z.A.; Ostrovskaya, L.A.; Bluchterova, N.V.; Fomina, M.M. oCarboxybenzoylferrocene. Bioactivity and chemical Modifications. Appl. Organomet. Chem. 2008, 22, 276-280. [CrossRef]

23. Wani, W.A.; Jameel, E.; Baig, U.; Mumtazuddin, S.; Hun, L.T. Ferroquine and its derivatives: New generation of antimalarial agents. Eur. J. Med. Chem. 2015, 101, 534-551. [CrossRef] [PubMed]

24. Peter, S.; Aderibigbe, B.A. Ferrocene-based compounds with antimalaria/anticancer activity. Molecules 2019, 24, 3604. [CrossRef]

25. Patra, M.; Gasser, G. The medicinal chemistry of ferrocene and its derivatives. Nat. Chem. Rev. 2017, 1, 0066. [CrossRef] 
26. Sansook, S.; Hassell-Hart, S.; Ocasio, C.; Spencer, J. Ferrocenes in medicinal chemistry; a personal perspective. J. Organomet. Chem. 2020, 905, 121017. [CrossRef]

27. Braga, S.S.; Silva, A.M.S. A New Age for Iron: Antitumoral Ferrocenes. Organometallics 2013, 32, 5626-5639. [CrossRef]

28. Jaouen, G.; Vessieres, A.; Top, S. Ferrocifen type anti cancer drugs. Chem. Soc. Rev. 2015, 44, 8802-8817. [CrossRef]

29. Wang, Y.; Dansette, P.M.; Pigeon, P.; Top, S.; McGlinchey, M.J.; Mansuy, D.; Jaouen, G. A new generation of ferrociphenols leads to a great diversity of reactive metabolites, and exhibits remarkable antiproliferative properties. Chem. Sci. 2018, 9, 70-78. [CrossRef] [PubMed]

30. Gibson, D. The mechanism of action of platinum anticancer agents-What do we really know about it? Dalton Trans. 2009, 10681-10689. [CrossRef]

31. Marchetti, F. Constructing Organometallic Architectures from Aminoalkylidyne Diiron Complexes. Eur. J. Inorg. Chem. 2018, 3987-4003. [CrossRef]

32. Busetto, L.; Marchetti, F.; Mazzoni, R.; Salmi, M.; Zacchini, S.; Zanotti, V. [3+2+1] cycloaddition involving alkynes, CO and bridging vinyliminium ligands in diiron complexes: A dinuclear version of the Dötz reaction? Chem. Commun. 2010, 46, 3327-3329. [CrossRef]

33. Marchetti, F.; Zacchini, S.; Zanotti, V. Photochemical Alkyne Insertions into the Iron - Thiocarbonyl Bond of $\left[\mathrm{Fe}_{2}(\mathrm{CS})(\mathrm{CO})_{3}(\mathrm{Cp})_{2}\right]$. Organometallics 2016, 35, 2630-2637. [CrossRef]

34. Marchetti, F.; Zacchini, S.; Zanotti, V. Carbon monoxide-isocyanide coupling promoted by acetylide addition to a diiron complex Chem. Commun. 2015, 51, 8101-8104. [CrossRef] [PubMed]

35. Boni, A.; Funaioli, T.; Marchetti, F.; Pampaloni, G.; Pinzino, C.; Zacchini, S. Reversible Reductive Dimerization of Diiron $\mu$-Vinyl Complex via C-C Coupling: Characterization and Reactivity of the Intermediate Radical Species. Organometallics 2011, 30, 4115-4122. [CrossRef]

36. Agonigi, G.; Biancalana, L.; Lupo, M.G.; Montopoli, M.; Ferri, N.; Zacchini, S.; Binacchi, F.; Biver, T.; Campanella, B.; Pampaloni, G.; et al. Exploring the Anticancer Potential of Diiron Bis-cyclopentadienyl Complexes with Bridging Hydrocarbyl Ligands: Behavior in Aqueous Media and In Vitro Cytotoxicity. Organometallics 2020, 39, 645-657. [CrossRef]

37. Biancalana, L.; De Franco, M.; Ciancaleoni, G.; Zacchini, S.; Pampaloni, G.; Gandin, V.; Marchetti, F. Easily Available and Amphiphilic Diiron Cyclopentadienyl Complexes Exhibit In Vitro Anticancer Activity in 2D and 3D Human Cancer Cells via Redox Modulation Triggered by CO Release. Chem. Eur. J. 2021, 27, 10169-10185. [CrossRef]

38. Schoch, S.; Batchelor, L.K.; Funaioli, T.; Ciancaleoni, G.; Zacchini, S.; Braccini, S.; Chiellini, F.; Biver, T.; Pampaloni, G.; Dyson, P.J.; et al. Diiron Complexes with a Bridging Functionalized Allylidene Ligand: Synthesis, Structural Aspects, and Cytotoxicity. Organometallics 2020, 39, 361-373. [CrossRef]

39. Rocco, D.; Batchelor, L.K.; Agonigi, G.; Braccini, S.; Chiellini, F.; Schoch, S.; Biver, T.; Funaioli, T.; Zacchini, S.; Biancalana, L.; et al. Anticancer Potential of Diiron Vinyliminium Complexes. Chem. Eur. J. 2019, 25, 14801-14816. [CrossRef] [PubMed]

40. Agonigi, G.; Batchelor, L.K.; Ferretti, E.; Schoch, S.; Bortoluzzi, M.; Braccini, S.; Chiellini, F.; Biancalana, L.; Zacchini, S.; Pampaloni, G.; et al. Mono-, Di- and Tetra-iron Complexes with Selenium or Sulphur Functionalized Vinyliminium Ligands: Synthesis, Structural Characterization and Antiproliferative Activity. Molecules 2020, 25, 1656. [CrossRef]

41. Mazzoni, R.; Salmi, M.; Zanotti, V. C-C Bond Formation in Diiron Complexes. Chem. Eur. J. 2012, 18, 10174-10194. [CrossRef] [PubMed]

42. Ritleng, V.; Chetcuti, M.J. Hydrocarbyl Ligand Transformations on Heterobimetallic Complexes. Chem. Rev. 2007, 107, 797-858. [CrossRef]

43. García, M.E.; García-Vivó, D.; Ramos, A.; Ruiz, M.A. Phosphinidene-bridged binuclear complexes. Coord. Chem. Rev. 2017, 330, 1-36. [CrossRef]

44. Ciancaleoni, G.; Zacchini, S.; Zanotti, V.; Marchetti, F. DFT Mechanistic Insights into the Alkyne Insertion Reaction Affording Diiron $\mu$-Vinyliminium Complexes and New Functionalization Pathways. Organometallics 2018, 37, 3718-3731. [CrossRef]

45. Rocco, D.; Busto, N.; Pérez-Arnaiz, C.; Biancalana, L.; Zacchini, S.; Pampaloni, G.; Garcia, B.; Marchetti, F. Antiproliferative and bactericidal activity of diiron and monoiron cyclopentadienyl carbonyl complexes comprising a vinyl-aminoalkylidene unit. Appl. Organomet. Chem. 2020, 34, e5923. [CrossRef]

46. Schoch, S.; Mouna, H.; Pereira, S.A.P.; Saraiva, M.L.M.F.S.; Braccini, S.; Chiellini, F.; Biver, T.; Zacchini, S.; Pampaloni, G.; Dyson, P.J.; et al. A Simple Strategy to Incorporate Bioactive Fragments in Anticancer Diiron Bis-Cyclopentadienyl Complexes. Organometallics 2021. [CrossRef]

47. Agonigi, G.; Bortoluzzi, M.; Marchetti, F.; Pampaloni, G.; Zacchini, S.; Zanotti, V. Regioselective Nucleophilic Additions to Diiron Carbonyl Complexes Containing a Bridging Aminocarbyne Ligand: A Synthetic, Crystallographic and DFT Study. Eur. J. Inorg. Chem. 2018, 960-971. [CrossRef]

48. Menges, F. “Spectragryph—Optical Spectroscopy Software”, Version 1.2.5, @2016-2017. Available online: http:/ /www.effemm2.de/ spectragryph.

49. Fulmer, G.R.; Miller, A.J.M.; Sherden, N.H.; Gottlieb, H.E.; Nudelman, A.; Stoltz, B.M.; Bercaw, J.E.; Goldberg, K.I. NMR Chemical Shifts of Trace Impurities: Common Laboratory Solvents, Organics, and Gases in Deuterated Solvents Relevant to the Organometallic Chemist. Organometallics 2010, 29, 2176-2179. [CrossRef]

50. Willker, W.; Leibfritz, D.; Kerssebaum, R.; Bermel, W. Gradient selection in inverse heteronuclear correlation spectroscopy. Magn. Reson. Chem. 1993, 31, 287-292. [CrossRef] 
51. Albano, V.G.; Busetto, L.; Monari, M.; Zanotti, V. Reactions of acetonitrile di-iron $\mu$-aminocarbyne complexes; synthesis and structure of $\left.\left[\mathrm{Fe}_{2}(\mu-\mathrm{CNMe})_{2}\right)(\mu-\mathrm{H})(\mathrm{CO})_{2}(\mathrm{Cp})_{2}\right]$. J. Organomet. Chem. 2000, 606, 163-168. [CrossRef]

52. Busetto, L.; Marchetti, F.; Zacchini, S.; Zanotti, V. Unprecedented Zwitterionic Iminium-Chalcogenide Bridging Ligands in Diiron Complexes. Organometallics 2006, 25, 4808-4816. [CrossRef]

53. IR Data of Acetonitrile Adducts ( $\tilde{v} / \mathrm{cm}-1$, Acetonitrile Solution): 1984vs (CO), 1817s ( $\mu-\mathrm{CO}), 1531 \mathrm{w}-\mathrm{m}$ ( $\mu-\mathrm{CN})$ (from 1a); 1984vs (CO), 1813s ( $\mu-\mathrm{CO}), 1571 \mathrm{~m}(\mu-\mathrm{CN})$ (from 1b); 1981vs (CO), 1812s ( $\mu-\mathrm{CO}), 1551 \mathrm{w}(\mu-\mathrm{CN})$ (from 1c); 1984vs (CO), 1814s ( $\mu-\mathrm{CO})$, $1563 \mathrm{w}-\mathrm{m}(\mu-\mathrm{CN})$ (from 1d) [51]; 1984vs (CO), 1814s ( $\mu$-CO) (from 1e) [52]; 1986vs (CO), 1815s ( $\mu-\mathrm{CO}), 1527 \mathrm{w}$ ( $\mu-\mathrm{CN})($ from 1f)

54. Sheldrick, G.M. SADABS-2008/1-Bruker AXS Area Detector Scaling and Absorption Correction; Bruker AXS: Madison, WI, USA, 2008.

55. Sheldrick, G.M. Crystal structure refinement with SHELXL. Acta Crystallogr. C 2015, 71, 3-8. [CrossRef]

56. Spek, A.L. PLATON, A Multipurpose Crystallographic Tool; Utrecht University: Utrecht, The Netherlands, 2005.

57. Rundlöf, T.; Mathiasson, M.; Bekiroglu, S.; Hakkarainen, B.; Bowden, T.; Arvidsson, T. Survey and qualification of internal standards for quantification by ${ }^{1} \mathrm{H}$ NMR spectroscopy. J. Pharm. Biomed. Anal. 2010, 52, 645-651. [CrossRef]

58. Rice, N.M.; Irving, H.M.N.H.; Leonard, M.A. Nomenclature for liquid-liquid distribution (solvent extraction). Pure Appl. Chem. 1993, 65, 2373-2396. [CrossRef]

59. OECD Guidelines for Testing of Chemicals; OECD: Paris, France, 1995; Volume 107.

60. Dearden, J.C.; Bresnen, G.M. The Measurement of Partition Coefficients. Quant. Struct. Act. Relat. 1988, 7, 133-144. [CrossRef]

61. Currie, D.J.; Lough, C.E.; Silver, R.F.; Holmes, H.L. Partition Coefficients Of Some Conjugated Heteroenoid Compounds and 1,4-Naphthoquinones. Can. J. Chem. 1966, 44, 1035-1043. [CrossRef]

62. Rosenkranz, A.R.; Schmaldienst, S.; Stuhlmeier, K.M.; Chen, W.; Knapp, W.; Zlabinger, G.J. A microplate assay for the detection of oxidative products using $2^{\prime}, 7^{\prime}$-dichlorofluorescin-diacetate. J. Immunol. Methods 1992, 156, 39-45. [CrossRef]

63. Fabbrini, M.G.; Cirri, D.; Pratesi, A.; Ciofi, L.; Marzo, T.; Guerri, A.; Nistri, S.; Dell'Accio, A.; Gamberi, T.; Severi, M.; et al. A Fluorescent Silver(I) Carbene Complex with Anticancer Properties: Synthesis, Characterization, and Biological Studies. ChemMedChem 2019, 14, 182-188. [CrossRef] [PubMed]

64. Zoppi, C.; Massai, L.; Cirri, D.; Gabbiani, C.; Pratesi, A.; Messori, L. Protein metalation by two structurally related gold(I) carbene complexes: An ESI MS study. Inorg. Chim. Acta 2021, 520, 120297. [CrossRef]

65. Albano, V.G.; Busetto, L.; Marchetti, F.; Monari, M.; Zacchini, S.; Zanotti, V. Stereochemistry of the insertion of disubstituted alkynes into the metal aminocarbyne bond in diiron complexes. J. Organomet. Chem. 2004, 689, 528-538. [CrossRef]

66. Albano, V.G.; Busetto, L.; Marchetti, F.; Monari, M.; Zacchini, S.; Zanotti, V. Diiron $\mu$-Vinyliminium Complexes from Acetylene Insertion into a Metal-Aminocarbyne Bond. Organometallics 2003, 22, 1326-1331. [CrossRef]

67. Zhao, J.; Gou, S.; Liu, F. Potent Anticancer Activity and Possible Low Toxicity of Platinum(II) Complexes with Functionalized 1,1-Cyclobutanedicarboxylate as a Leaving Ligand. Chem. Eur. J. 2014, 20, 15216-15225. [CrossRef]

68. Gust, R.; Krauser, R.; Schmid, B.; Schönenberger, H. Breast cancer inhibiting diastereomeric diacetato[1,2-bis(4-fluorophenyl) ethylenediamine]platinum(II) derivatives: Synthesis and studies on the relationship between reactivity and antitumor activity. Inorg. Chim. Acta 1996, 250, 203-218. [CrossRef]

69. Gust, R.; Krauser, R.; Schmid, B.; Schönenberger, H. Synthesis and Antitumor Activity of [1,2-Bis(4-fluorophenyl)ethylenediamine] [dicarboxylato]platinum(II) Complexes. Arch. Pharm. Pharm. Med. Chem. 1998, 331, 27-35. [CrossRef]

70. Marloye, M.; Berger, G.; Gelbcke, M.; Dufrasne, F. A survey of the mechanisms of action of anticancer transition metal complexes. Future Med. Chem. 2016, 8, 2263-2286. [CrossRef] [PubMed]

71. We Previously Found that the Precipitate Formed upon Maintaining Various Complexes Based on the $\{\mathrm{Fe} 2 \mathrm{Cp} 2(\mathrm{CO}) \mathrm{x}\} \mathrm{Core}(\mathrm{x}=2$ or 3) in Aqueous Solution Always Corresponds to Some Form of iron(III) oxide [37, 39]

72. Marchetti, F.; Di Nicola, C.; Pettinari, R.; Pettinari, C.; Aiello, I.; La Deda, M.; Candreva, A.; Morelli, S.; De Bartolo, L.; Crispini, A. Zinc(II) Complexes of Acylpyrazolones Decorated with a Cyclohexyl Group Display Antiproliferative Activity Against Human Breast Cancer Cells. Eur. J. Inorg. Chem. 2020, 1027-1039. [CrossRef]

73. Akhmetova, V.R.; Akhmadiev, N.S.; Abdullin, M.F.; Dzhemileva, L.U.; Dyakonov, V.A. Synthesis of new N,N-Pd(Pt) complexes based on sulfanyl pyrazoles, and investigation of their in vitro anticancer activity. RSC Adv. 2020, 10, 15116-15123. [CrossRef]

74. Zanda, E.; Busto, N.; Biancalana, L.; Zacchini, S.; Biver, T.; Garcia, B.; Marchetti, F. Anticancer and antibacterial potential of robust Ruthenium(II) arene complexes regulated by choice of $\alpha$-diimine and halide ligands. Chem. Biol. Interact. 2021, $344,109522$. [CrossRef] [PubMed]

75. Scalcon, V.; Salmain, M.; Folda, A.; Top, S.; Pigeon, P.; Shirley, L.H.Z.; Jaouen, G.; Bindoli, A.; Vessières, A.; Rigobello, M.P. Tamoxifen-like metallocifens target the thioredoxin system determining mitochondrial impairment leading to apoptosis in Jurkat cells. Metallomics 2017, 9, 949-959. [CrossRef]

76. Casini, A.; Mastrobuoni, G.; Ang, W.H.; Gabbiani, C.; Pieraccini, G.; Moneti, G.; Dyson, P.J.; Messori, L. ESI-MS Characterisation of Protein Adducts of Anticancer Ruthenium(II)-Arene PTA (RAPTA) Complexes. ChemMedChem 2007, 2, 631-635. [CrossRef]

77. Pratesi, A.; Cirri, D.; Ciofi, L.; Messori, L. Reactions of Auranofin and Its Pseudohalide Derivatives with Serum Albumin Investigated through ESI-Q-TOF MS. Inorg. Chem. 2018, 57, 10507-10510. [CrossRef]

78. Pelosi, C.; Saitta, F.; Zerino, C.; Canil, G.; Biver, T.; Pratesi, A.; Duce, C.; Fessas, D.; Gabbiani, C.; Tiné, M.R. Thermodynamic Evaluation of the Interactions between Anticancer Pt(II) Complexes and Model Proteins. Molecules 2021, 26, 2376. [CrossRef]

79. Zoppi, C.; Messori, L.; Pratesi, A. ESI MS studies highlight the selective interaction of Auranofin with protein free thiols. Dalton Trans. 2020, 49, 5906-5913. [CrossRef] 
80. Massai, L.; Zoppi, C.; Cirri, D.; Pratesi, A.; Messori, L. Reactions of Medicinal Gold(III) Compounds With Proteins and Peptides Explored by Electrospray Ionization Mass Spectrometry and Complementary Biophysical Methods. Front. Chem. 2020, $8,581648$. [CrossRef] [PubMed]

81. Massai, L.; Pratesi, A.; Bogojeski, J.; Banchini, M.; Pillozzi, S.; Messori, L.; Bugarčić, Ž.D. Antiproliferative properties and biomolecular interactions of three Pd(II) and Pt(II) complexes. J. Inorg. Biochem. 2016, 165, 1-6. [CrossRef] [PubMed]

82. Pratesi, A.; Gabbiani, C.; Michelucci, E.; Ginanneschi, M.; Papini, A.M.; Rubbiani, R.; Ott, I.; Messori, L. Insights on the mechanism of thioredoxin reductase inhibition by gold N-heterocyclic carbene compounds using the synthetic linear selenocysteine containing C-terminal peptide hTrxR(488-499): An ESI-MS investigation. J. Inorg. Biochem. 2014, 136, 161-169. [CrossRef]

83. Tŏpala, T.; Pascual-Álvarez, A.; Moldes-Tolosa, M.Á.; Bodoki, A.; Castiñei ras, A.; Torres, J.; del Pozo, C.; Borrás, J.; Alzuet-Piña, G. New sulfonamide complexes with essential metal ions [Cu(II), Co(II), Ni(II) and $\mathrm{Zn}(\mathrm{II})]$. Effect of the geometry and the metal ion on DNA binding and nuclease activity. BSA protein interaction. J. Inorg. Biochem. 2020, 202, 110823. [CrossRef] [PubMed]

84. Elsadek, B.; Kratz, F. Impact of albumin on drug delivery-New applications on the horizon. J. Control. Release 2012, 157, 4-28. [CrossRef] [PubMed] 